\title{
New titanosauriform (Dinosauria: Sauropoda ) specimens from the Upper Cretaceous Daijiaping Formation of southern China
}

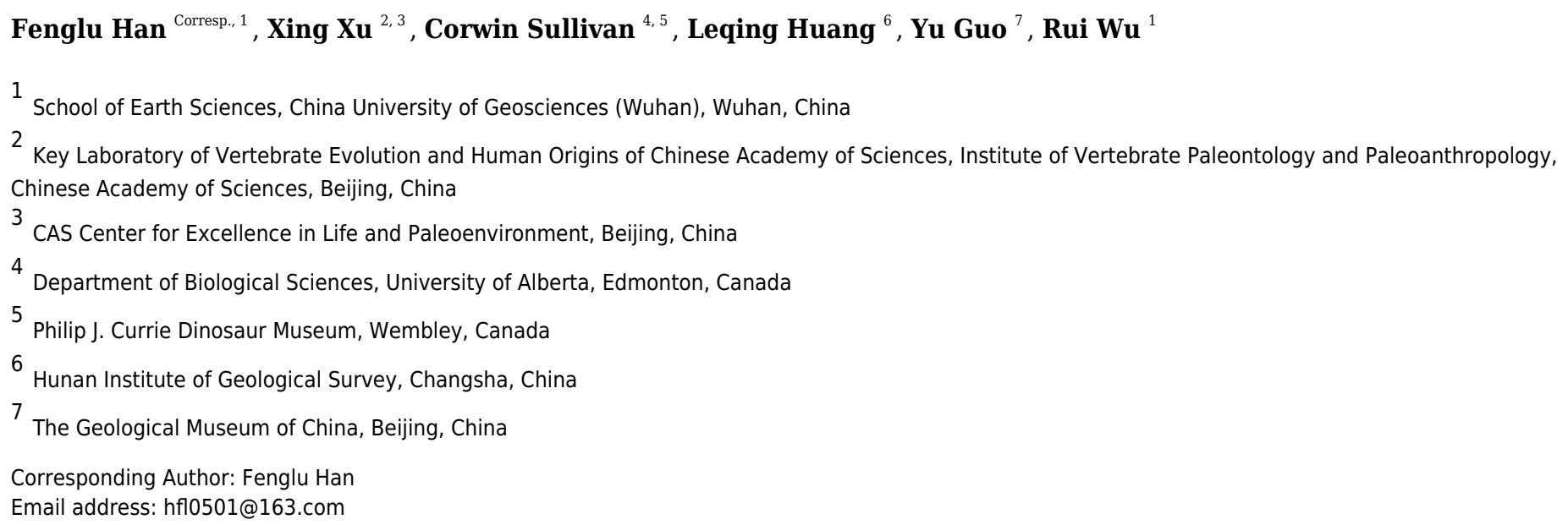

Titanosauriform sauropod dinosaurs were once considered rare in the Upper Cretaceous of Asia, but a number of titanosauriforms from this stratigraphic interval have been discovered in China in recent years. In fact, all adequately known Cretaceous Asian sauropods are titanosauriforms, but only a few have been well studied, lending significance to any new anatomical information that can be extracted from Asia's Cretaceous sauropod record. Here we give a detailed description of some titanosauriform bones recovered recently from the Upper Cretaceous Daijiaping Formation of Tianyuan County, Zhuzhou City, Hunan Province, southern China. The occurrence of this material in Hunan increases the known geographic range of titanosauriforms in eastern Asia. Although all of the specimens discussed in this paper can be assigned to Titanosauriformes at least tentatively, some bones display a limited number of features that are more typical of basal sauropods and/or derived diplodocoids, suggesting complex patterns of character evolution within Neosauropoda. 


\section{New titanosauriform (Dinosauria: Sauropoda) specimens}

\section{2 from the Upper Cretaceous Daijiaping Formation of}

\section{3 southern China}

4

5

6

7 Fenglu Han ${ }^{1}$, Xing Xu ${ }^{2,3}$, Corwin Sullivan ${ }^{4}, 5$, Leqing Huang 6 , Yu Guo ${ }^{7}$, Rui Wu ${ }^{1}$

8

$9{ }^{1}$ School of Earth Sciences, China University of Geosciences (Wuhan), Wuhan, China

${ }^{2}$ Key Laboratory of Vertebrate Evolution and Human Origins of Chinese Academy of Sciences, Institute of Vertebrate Paleontology and Paleoanthropology, Chinese Academy of Sciences, Beijing, China

${ }^{3}$ CAS Center for Excellence in Life and Paleoenvironment, Beijing, China

${ }^{4}$ Department of Biological Sciences, University of Alberta, Edmonton, Canada

${ }^{5}$ Philip J. Currie Dinosaur Museum, Wembley, Canada

${ }^{6}$ Hunan Institute of Geological Survey, Changsha, China

7 The Geological Museum of China, Beijing, China

1 Corresponding Author:

2 Fenglu Han ${ }^{1}$

3

4 Email address: hanfl@cug.edu.cn 


\section{Abstract}

28 Titanosauriform sauropod dinosaurs were once considered rare in the Upper Cretaceous of Asia, 29 but a number of titanosauriforms from this stratigraphic interval have been discovered in China 30 in recent years. In fact, all adequately known Cretaceous Asian sauropods are titanosauriforms, 31 but only a few have been well studied, lending significance to any new anatomical information 32 that can be extracted from Asia's Cretaceous sauropod record. Here we give a detailed 33 description of some titanosauriform bones recovered recently from the Upper Cretaceous Daijiaping Formation of Tianyuan County, Zhuzhou City, Hunan Province, southern China. The occurrence of this material in Hunan increases the known geographic range of titanosauriforms in eastern Asia. Although all of the specimens discussed in this paper can be assigned to Titanosauriformes at least tentatively, some bones display a limited number of features that are more typical of basal sauropods and/or derived diplodocoids, suggesting complex patterns of character evolution within Neosauropoda.

\section{Introduction}

By the dawn of the Cretaceous, the diversity of sauropod dinosaurs had been reduced to the major clades Diplodocoidea and Titanosauriformes, which differed greatly in their subsequent evolutionary fortunes (Wilson 2005; Whitlock 2011; D’Emic 2012; Fanti et al. 2015). Rebbachisaurid diplocoids underwent a modest radiation in the Early Cretaceous, and a few persisted into the early Late Cretaceous in Africa, Europe and South America, but diplodocoids were less diverse even in the Early Cretaceous than they had been in the Late Jurassic. Titanosauriforms, by contrast, achieved a worldwide distribution and a high level of diversity during the Early Cretaceous, and were among the most successful herbivorous dinosaur groups of the Late Cretaceous. Although titanosauriforms were once thought to have been relatively rare in China, it was eventually realized that all known Chinese Cretaceous sauropods were titanosauriforms (e.g. Whitlock et al. 2011), and a series of discoveries have shown that the diversity of this group in China was substantial. To date, nine titanosauriform genera have been described from the Upper Cretaceous of China (Fig. 1), including Sonidosaurus from the Erlian Formation of Inner Mongolia (Xu et al. 2006), Borealosaurus from the Sunjiawan Formation of Liaoning Province (You et al. 2004), Huabeisaurus from the Huiquanpu Formation of Shanxi Province (Pang \& Cheng 2000), Zhuchengtitan from the Wangshi Group of Shandong Province 8 (Mo et al. 2017), Gannansaurus from the Nanxiong Formation of Jiangxi Province (Lü et al. 59 2013b), Qingxiusaurus from Upper Cretaceous red beds in Guangxi Province (Mo et al. 2008), 
60 Jiangshanosaurus and Dongyangosaurus from the Jinhua Formation of Zhejiang Province (Tang 61 et al., 2001; Lü et al. 2008; Yu et al., 2010), and Baotianmansaurus from the Xiaguan Formation 62 of Henan Province (Zhang et al. 2009; Wang et al., 2013). The situation in China conforms to a 63 wider biogeographic pattern, in that Titanosauriformes is the only sauropod clade known to have 64 been present in the Cretaceous of Asia as a whole (Wilson, 2005; Wilson and Upchurch, 2009). 65 In the Jurassic, by contrast, the sauropod fauna of China was overwhelmingly dominated by 66 basal (non-neosauropod) taxa, the only known Chinese diplodocoid being the recently described Lingwulong from the Toarcian-Bajocian of Ningxia (Xu et al. 2018).

68

In 2008, a new fossil site containing numerous dinosaur bones was discovered in the Upper Cretaceous Daijiaping Formation of Tianyuan County, Zhuzhou City, Hunan Province, southern China (Fig. 1). The site is on the east side of Lianhua Road, in the northern part of Tianyuan County, and was the intended location of a new middle school. Prior to construction of the school, workers were using explosives to level an area of elevated terrain when a crew member named Dangsheng Fang noticed fragments resembling animal bones among the shattered rock. Some of these fossils were sent to experts from the Institute of Vertebrate Paleontology and Paleoanthropology in Beijing, who identified them as dinosaur bones. The local government protected the site immediately and arranged for all visible fossils to be collected. More than 200 bones were gathered and apportioned between the Zhuzhou Museum and the Bureau of Land and Resources of Zhuzhou City. Most of the bones were fragmented and displaced by the explosives, and are consequently difficult to identify (Han et al., 2017) or to assign to particular beds, but some remained in place so that their stratigraphic positions could be documented as they were collected (Fig. 2).

The dinosaur bones occurred within an area of about $6,000 \mathrm{~m}^{2}$ and within strata of the Daijiaping Formation, which includes a lower portion consisting of sandstone and an upper portion consisting of siltstone and mudstone. On a regional scale, the total thickness of the formation is about $1 \mathrm{~km}$. However, the beds exposed at the site span only $50 \mathrm{~m}$ of thickness and are believed to represent a transitional region between the lower and upper parts of the formation. The exposed beds can be divided into three parts: a lower part consisting of red calcareous siltstone, interspersed with conglomerate layers; a middle part consisting of alternating siltstone and conglomerate beds, and containing the dinosaur bones; and an upper part mainly consisting of siltstone (Fig. 2). The dinosaur bones were recovered from six units in the middle part of the section, within a stratigraphic interval ranging in thickness from 8.6 to $16.0 \mathrm{~m}$ across the width of the outcrop (Fig. 2). The Daijiaping Formation is generally considered to date from the early Late Cretaceous (Coniacian to Santonian) (Han et al. 2017). However, analysis of a total of 22 
96 pollen samples from layers 4 and 9, situated in the middle part of the exposed section, instead

97 98

99

100

101

102

103

104

105

106

107

108

109

110

111

112

113

114

115

116

117

118

119

120

121

122

123

124

125

126

127

128

129

suggests a latest Cretaceous (Campanian to Maastrichtian) age (Zhu et al. 2019).

A preliminary study (Han et al., 2017) concluded that the sample of bones from this locality might contain two types of sauropod, and several species of theropod and hadrosaur. These bones are disarticulated and appear to have been rapidly buried in the course of a flooding event following transport over a short distance, as the clasts in the conglomerate are poorly rounded. Sauropod bones are particularly abundant in the sample, and Han et al. (2017) identified derived features suggesting that some of these bones were of titanosauriform origin whereas at least one, the left ischium ZMW148, was potentially from a diplodocoid. Relatively complete sauropod bones are known from the third and eighth units in the middle part of the section. The third unit is composed of siltstone and mainly contains cervical fragments, whereas the eighth is composed of conglomerate and is even richer in sauropod fossils, having produced the complete fibula, humerus, and ischium described here in addition to many unidentified fragments (Fig. 2).

Here, we present the first detailed study of the anatomically informative sauropod bones from the Tianyuan site, and reconsider their probable affinities within Sauropoda. The bones in the sample are not all proportionate in size to one another (see Tables 1-3) and in any case came from multiple stratigraphic levels, so multiple individuals are clearly represented. The bones may represent either a single species or multiple species.

Institutional Abbreviations: AODF, Australian Age of Dinosaurs, Winton, Queensland, Australia; BYU, Brigham Young University, Earth Sciences Museum, Provo, Utah, USA; HMN, Humboldt Museum für Naturkunde, Berlin, Germany; ZGT, Bureau of Land and Resources of Zhuzhou City, Zhuzhou, Hunan, China; ZMW, Zhuzhou Museum, Zhuzhou, Hunan, China.

\section{Materials \& Methods}

All specimens described here are postcranial bones, including the following elements: ZGT002, a partial cervical vertebra lacking the posterior part; ZGT012, a partial cervical with the left rib preserved in articulation; ZGT005, two articulated, very incomplete cervical centra; ZGT044 and ZGT013, partial cervical ribs; ZGT003, a nearly complete caudal vertebra lacking the neural spine; ZMW143, a partial scapula; ZGT056-060, the well-preserved proximal half of a humerus; ZGT089, a midshaft fragment of a small humerus; ZMW148, a complete left ischium; ZMW5157, a nearly complete fibula; and ZMW013, an almost complete pedal ungual. Some of these 
130 specimens are housed in the Bureau of Land and Resources of Zhuzhou City (ZGT), while others 131 are in the Zhuzhou Museum (ZMW). Measurements of all these bones are presented in Tables 1132 3. Comparisons with other taxa were mainly based on published literature and photographs.

133 High-resolution 3D models of the cervical vertebra ZGT002 and the left ischium ZMW 148 are 134 available in morphosourse.org, at

135 https://www.morphosource.org/Detail/MediaDetail/Show/media_id/51457 for ZGT002 and 136 https://www.morphosource.org/Detail/MediaDetail/Show/media id/51458 for ZMW148. These 137 bones were scanned using an Artec Space Spider hand-held 3D Scanner, and the scan data were 138 edited to produce the final 3D models using Artec Studio.

139

140 Definitions of clades used in this study follow Mannion et al. (2013).

\section{Results}

\section{Systematic Paleontology}

144

145 Saurischia Seeley, 1887

146 Sauropoda Marsh, 1878

147 Neosauropoda Bonaparte, 1996

148 Macronaria Wilson \& Sereno, 1998

149 Titanosauriformes Salgado, Coria and Calvo, 1997

150 Titanosauriformes indet.

151

152 Description and comparisons.

153 Cervical vertebrae and ribs. All of the cervical vertebrae described here were excavated from 154 layer 3 , in the middle part of the exposed section (Fig. 2). Two partial cervical vertebrae 155 (ZGT002 and ZGT012), both with associated ribs, were identified (Figs. 3, 4). ZGT002 is the 156 better-preserved of the two and also exhibits some distinctive features. A detailed description of 157 ZGT002, supplemented in places by information from the much less complete ZGT012, follows 158 below. Measurements of ZGT002 are given in Table 1.

159

160 The anterior part of the centrum is well-preserved, but has undergone strong diagenetic 161 compression in the dorsoventral direction. The portion of the centrum posterior to the 162 diapophysis is broken away. The anterior articular surface is strongly convex, with a subcircular 163 outline. The position of this partial vertebra within the cervical series is hard to assess with 
164

165

166

167

168

169

170

171

172

173

174

175

176

177

178

179

180

181

182

183

184

185

186

187

188

189

190

191

192

193

194

195

196

197

198

199

certainty, but on balance the specimen seems most likely to be from the anterior part of the neck.

The most prominent part of the anterior condyle is displaced dorsally from the center of the articular surface as in the anterior and middle cervicals of the basal (non-titanosaurian) titanosauriform Euhelopus (Wilson \& Upchurch 2009), although in the anterior cervicals of Erketu and Yunmenglong the convexity of the anterior condyle is more uniform (Ksepka \& Norell 2006; Lü et al. 2013a). The lateral surface of the centrum is slightly concave, which are more consistent with attribution to the anterior part of the cervical column, as posterior cervicals tend to bear more elaborate laminae and pneumatic cavities than anterior ones (Gomani 2005).

The neural spine is missing, but the cross section of the broken base of the spine is thin and short, suggesting that the intact spine would have been of the poorly developed type expected in an anterior cervical. In Euhelopus the neural spines become transversely wide and bifurcated posterior to cervical 11 (Wilson \& Upchurch 2009). If ZGT002 is indeed an anterior cervical vertebra, comparison with the anterior cervicals of Erketu (Ksepka \& Norell 2006) suggests that more than half of the centrum is missing.

The left lateral surface of the centrum is depressed, and the ventral part of this surface is further excavated by an anteroposteriorly elongate fossa that can be clearly seen in posterior view (Fig. $3 \mathrm{~F}$ ) and also in the 3D model. The anterior cervical centra of Erketu display a similar condition, albeit with a deeper fossa (Ksepka and Norell, 2006). In comparison, $t$ wo or three pairs of small deep pleurocoels occur in the anterior cervicals of Yunmenlong (Lü et al. 2013a) and Qiaowanlong (You \& Li 2009), whereas in the preserved posterior cervical vertebrae of the titanosauriforms Daxiatitan and Yongjinglong only a single large, deep fossa is present on each lateral surface of the centrum (You et al. 2008; Li et al. 2014).

In ventrolateral view, it can be clearly seen that the neural arch is excavated by two infradiapophyseal fossa separated by a prominent, posterodorsally oriented ridge (ppr, Fig. 3A). This ridge is more robust in ZGT012 than in ZGT002 (Fig. 4B). In ZGT012, a small, deep fossa penetrates the widened posterodorsal end of the lamina (fo, Fig. 4B). The anterior infradiapophyseal fossa is subtriangular in lateral view, whereas the posterior one is elongate and shallow dorsoventrally. In ZGT002, a weak, vertically oriented secondary ridge separates the posterior fossa into an anterior subrectangular compartment and a posterior shallow triangular compartment (Fig. 3A).

In ZGT002 the diapophysis arises from the dorsal portion of the centrum and has been deflected upward as a result of distortion (Fig. 3C, G). A narrow process extends ventrolaterally from near the anterior end of the anteroposteriorly elongate base of the diapophysis, so that the diapophysis 
200 as a whole has a rotated "L" shape in lateral view. On the left side of the vertebra, the base of the 201 diapophysis is embayed by small notches both anteriorly and posteriorly (Fig. 3C). On the right 202 side, however, only a posterior notch is present, suggesting that the anterior notch on the left 203 diapophysis is a result of damage (Fig. 3G). The ventral process of the diapophysis overlaps the

204

205

206

207

208

209

210

211

212

213

214

215

216

217

218

219

220

221

222

223

224

225

226

227

228

229

230

231

232

233

234 235

dorsolateral surface of the tuberculum. The long, shallow parapophysis extends laterally from the anteroventral corner of the centrum and is fused with the capitulum of the cervical rib. In other titanosauriforms such as Euhelopus, Erketu and Huabeisaurus (Ksepka and Norell 2006; Wilson \& Upchurch 2009; D'Emic et al. 2013), the parapophysis has a strong ventrolateral inclination, and the lateral orientation of the parapophysis of ZGT002 may be a result of taphonomic deformation.

The anterior part of the ventral surface of the centrum bears three adjacent large fossae, whereas the middle part bears a prominent midline keel (Fig. 3A, B). In many titanosauriforms (e.g. Qiaowanlong You \& Li 2009; Euhelopus Wilson \& Upchurch 2009), the ventral surface is concave and a keel is lacking. The right fossa is semicircular in outline and is relatively small and shallow, whereas the midline fossa has an oblong outline and is longer, narrower and deeper. The left fossa is similar in length to the midline fossa but is much wider, and semicircular in outline. The three fossae are separated by long, sharp ridges. A shallow depression is situated on the ventral surface of the midline keel, just posterior to the medial part of the left fossa, and is separated from the left fossa by a short but prominent transverse ridge. The shapes and sizes of the three fossae may be affected by the overall distortion of the vertebra. Cervical vertebrae with paired fossae in the same position as the three fossae seen in ZGT002 are known in some titanosaurs, including Rukwatitan (posterior cervical, Gorscak et al., 2014) and Overosaurus (posterior cervical, Coria et al., 2013). Paired fossae have also been reported in the cervicals of Lingwulong (Xu et al. 2018) and some other dicraeosaurids (Whitlock 2011), but these are separated by a keel (Tschopp, Mateus \& Benson 2015: Fig. 38) whereas in ZGT002 the ventral keel begins posterior to the fossae. In titanosaurs with paired fossae, the presence of a keel separating the fossae is variable (Gorscak et al. 2014).

The presence of a trio of fossae at the anterior end of the ventral surface of the centrum of ZGT002 is unusual, having never been reported in another sauropod cervical vertebra, and may potentially represent an autapomorphy indicating that at least some of the Zhuzhou sauropod material can be referred to a new species. However, we refrain from erecting a new species pending recovery of more complete specimens, particularly given the paucity of other clear potential autapomorphies in the material and the fact that pneumatic features such as fossae can be highly variable.

Peer] reviewing PDF | (2019:08:40330:1:1:NEW 3 Nov 2019) 
237 The keel occupying the middle part of the ventral surface of the centrum is transversely wide 238 anteriorly and narrows posteriorly, taking on a wedge-like shape. The keel essentially divides the 239 middle part of the ventral surface into two large, shallow depressions (Fig. 3B). A ventral keel is 240 a primitive character that appears in the cervicals of some non-neosauropods (e.g. Shunosaurus) 241 and some diplodocoids, occurring in most cervicals of Dicraeosaurus (Harris 2006: Fig. 2), the 242 middle and posterior cervicals of Kaatedocus (Tschopp \& Mateus 2013) and the only known 243 reasonably intact anterior cervical of Katepensaurus (Ibiricu et al. 2013: Fig. 3C). A ventral keel is also seen in some titanosauriform cervicals, such as the axis of Erketu (Ksepka \& Norell 2006:

245 Fig. 3), the axis and anterior cervicals of Mongolosaurus (Mannion, 2011: Fig. 6), the axis of

246 Futalognkosaurus (Mannion, 2011), the only known (posterior) cervical of Savannasaurus 247 (Poropat et al., 2016), and the cervicals of Rapetosaurus (Curry Rogers 2009). A weak midline 248 ridge is also present on the anterior part of the ventral surface of the centrum in cervicals 3 and 24917 of Euhelopus (Wilson \& Upchurch, 2009). Taken together, these observations imply that 250 ventral keels can occur throughout the cervical series in non-neosauropods, diplodocoids and titanosauriforms. The ventral keel seen in ZGT002 resembles those on the axial vertebrae of

252

253

254

255

256

257

258

259

260

261

262

263

264

265

266

267

268

269

270

271 Erketu and Mongolosaurus (Ksepka \& Norell 2006; Mannion 2011) in being transversely thickened anteriorly and becoming narrower and shallower posteriorly, providing more evidence that ZGT002 may represent an axis or anterior postaxial cervical.

Loss through breakage of the posterior portion of the centrum has resulted in the exposure of internal cavities. In posterior view, the interior of the centrum can be seen to be divided into two large chambers (camerae) by a longitudinal lamina (Fig. 3F), as in basal sauropods such as Camarasaurus (Wedel, Cifelli \& Sanders 2000). However, the interior of the neural arch region has a porous appearance, being divided irregularly into smaller chambers (camellae) as in titanosauriforms such as Euhelopus (Wilson \& Upchurch, 2009). The combination of a largely camerate centrum and an at least partly camellate neural arch is evident in basal titanosauriforms, such as Brachiosaurus (Wedel, Cifelli \& Sanders 2000: Fig. 12C, BYU12866), but differs from the fully camellate condition typically seen in derived titanosaurians, such as Saltasaurus (Wedel 2003).

There is no visible suture at the neurocentral junction, and the neural arch is damaged, although the neural canal is large. The pre- and postzygapophyses are missing. The PRDL

(prezygodiapophyseal lamina) is robust and extends posteroventrally from the lateral side of the prezygapophysis to the base of the diapophysis (Fig. 3C). Most of the neural spine is missing, but the preserved basal part is transversely thin, suggesting that this structure was non-bifid. In 
272 contrast, bifurcated neural spines with transversely thick bases are present in some of the 273 presacral vertebrae of many sauropods (Wedel \& Taylor 2013), including Euhelopus (Wilson \&

274 Upchurch 2009) and Erketu (Ksepka \& Norell 2006). The paired spinoprezygapophyseal laminae

275 are well-preserved, and are thin and deep with sharp edges. These laminae diverge

276 anterolaterally from the spine, forming between them an angle of $45^{\circ}$, and merge into the

277 prezygapophyses. There is no prespinal lamina or fossa.

278

279 In posterior view, it is evident that the centrum and neural arch are both distorted. The neural

280 canal is subrectangular, being dorsoventrally elongate and transversely narrow. The left

281 infrapostzygapophyseal fossa (ipozf, Fig. 3F) is well preserved. This fossa is subtriangular in

282 outline and bounded dorsolaterally by the postzygodiapophyseal lamina (PODL), ventrolaterally

283 by a laterally curved lamina, and medially by a vertical lamina that separates the fossa from the

284 neural canal. A second shallow fossa (fo, Fig. 3F) is situated just lateral to the large

285 infrapostzygopophyseal fossa. The small fossa is dorsoventrally elongate but transversely

286 narrow.

287

288 The anterior part of the left cervical rib belonging to ZGT002 is well-preserved, but the posterior 289 part is broken away. The rib shaft is robust and straight, and narrows dorsoventrally towards the 290 missing posterior end. The lateral surface is strongly dorsoventrally convex whereas the medial 291 surface is flatter, producing a semi-circular cross-section, as in the anterior to mid cervical ribs of 292 Kaatedocus (Tschopp and Mateus, 2013). The anterior part is divided into a slender dorsal 293 tuberculum and a deep, short ventral capitulum. The capitulum is fused to the parapophysis of 294 ZGT002 as described above, but the tuberculum is not fused to the diapophysis (Fig. 3A). Three 295 other cervical ribs are also well-preserved. In ZGT012, the tuberculum is fused to the 296 diapophysis, and the parapophysis and capitulum are broken away. The angle between the 297 tuberculum and capitulum is about $90^{\circ}$, as in basal sauropods such as Shunosaurus (Dong, Zhou 298 \& Zhang 1983), but may have been altered by preservational distortion. The cervical rib bears a 299 long anterior process, which is transversely narrow, tapers gradually to a point, and has a convex 300 lateral surface and a concave medial one. On the medial surface of the rib (Fig. 4B), a ridge 301 extends upwards from the base of the capitulum along the anterior margin of the tuberculum. 302 Most of the shaft is missing, but the base of the shaft is dorsoventrally deep and transversely 303 narrow. The capitulum is broken through near its medial end, and the cross-section shows several 304 small cavities.

305

306 Cervical ribs ZGT044 and ZGT013 are similar to each other but differ in size (Fig. 4). The 307 positions of these ribs within the cervical series are unknown. ZGT044 is double-headed, and 
308 fused at the capitulum and tuberculum to a fragment of the corresponding vertebra. In ZGT013,

309 the tuberculum is mostly broken away, whereas the capitulum is fused to a fragment of the

310 elongate parapophysis of the corresponding vertebra. A moderately well-developed ridge extends

311 posteromedially across the dorsal surface of the base of the posterior process (Fig. 4F). In both

312 these ribs, the angle between the capitulum and the tuberculum is about $45^{\circ}$, as in Omeisaurus

313 and neosauropods (Wilson \& Sereno 1998). The tuberculum is anteroposteriorly narrow, and has

314 a thin anterior margin but a thick posterior one. The capitulum is wide anteroposteriorly and thin

315 dorsoventrally. The dorsal surface of the capitulum bears a large, shallow fossa (Fig.4C, H), as in

316 some basal sauropods (Upchurch, Barrett \& Dodson 2004). The medial surface of the

317 tuberculum is visible in ZGT012, ZGT013, ZGT044. A robust vertical ridge emanates from the

318 midpoint of the base of the tuberculum and extends dorsally across the entire medial face,

319 curving posteriorly near its dorsal end (Fig. 4B, D, H).

320

321 The anterior and posterior processes of both ZGT044 and ZGT013 are well-developed. In both

322 cases the anterior process is slightly damaged at the tapering, anterodorsally curving tip, whereas

323 the posterior process is only partially preserved.

324

325 Caudal vertebra (ZGT003). A single, almost complete caudal vertebra (ZGT003) is present 326 (Fig. 5). This specimen appears to represent a middle caudal vertebra, based on its large size, 327 elongate proportions and lack of transverse processes. The centrum is $143 \mathrm{~mm}$ long, $100 \mathrm{~mm}$ 328 wide, and $109 \mathrm{~mm}$ tall (Table 1). By contrast, most sauropod anterior caudal centra, including 329 those of the the first eleven caudals of Tambatitanis (Saegusa \& Ikeda 2014) and the anterior 10 330 caudals of Huanghetitan ruyangensis (Lü et al. 2007), are wider than long. The length of the 331 centra tends to increase posteriorly along the caudal series (Upchurch et al. 2004), so that 332 centrum length and centrum width are usually about equal in caudals 10 to 15 (You, Tang \& Luo 333 2003). Therefore, ZGT003 is probably from the part of the tail posterior to caudal 10.

334

The centrum is slightly amphicoelous and subcylindrical, as in the middle caudals of basal titanosauriforms such as Gobititan (You, Tang \& Luo 2003) and Phuwiangosaurus (Martin 1999: Fig. 25, 26). In Huanghetitan ruyangensis, the anteriormost five caudal centra are amphicoelous, whereas those of caudals 6 to 10 are amphiplatyan (Lü et al. 2007). In contrast, the anterior and middle caudals are procoelous in some titanosauriforms, including Daxiatitan 340 (You et al. 2008) and Tambatitanis (Saegusa \& Ikeda 2014). In Mamenchisaurus, the 15

341 anteriormost caudal centra are procoelous, whereas the centra are amphiplatyan from caudal 16 342 onward (Young \& Zhao 1972). In Borealosaurus (You et al. 2004) and Fukuititan (Azuma \& 
343 Shibata 2010), the only preserved caudal centra are middle or distal in position, and are

344 opisthocoelous.

345

346 The lateral surface of the centrum is strongly dorsoventrally convex, and bears a weak

347 longitudinal ridge at about two-thirds of its height (Fig. 5B). The presence of the ridge gives the

348 cross-section of the centrum a hexagonal outline, as in the eighth and ninth caudal vertebrae of

349 Huanghetitan (Lü et al. 2007) and middle caudal vertebrae of the basal titanosaur Andesaurus

350 (Mannion \& Calvo 2011: Fig. 6). Several nutrient foramina are present on the lateral surfaces of

351 the centrum, as in Ganannosaurus (Lü et al. 2013b).

352

353 The anterior and posterior articular surfaces are both well-preserved and expanded

354 dorsoventrally, the anterior surface being the larger of the two. In anterior or posterior view, the

355 outline of the centrum resembles a hexagon with slightly convex sides and a slightly concave top

356 and bottom, the hexagon achieving its greatest transverse width at a level below its dorsoventral

357 midpoint. The ventral surface of the centrum is smoothly concave, and terminates anteriorly at a

358 transverse ridge (Fig. 5F). The apex of the concavity lies just below the posterior part of the

359 neural arch, and the ventral surface bears weak longitudinal ridges near its lateral margins (Fig.

360 5A). However, the ventral surface lacks a midline groove, a feature present in many forms

361 (Upchurch, Barrett \& Dodson 2004) including Huanghetitan (caudals 8 and 9, Lü et al. 2007).

362 The ventral surface also lacks the anteroposterior row of distinct fossae that occur in the anterior

363 caudals of derived diplodocids and lithostrotians (Upchurch, Barrett \& Dodson 2004).

364

365 The anterior and posterior pairs of chevron facets are both well-developed. The anterior facets

366 are convex, directed ventrally, and subcircular in outline. The posterior facets are relatively

367 flattened, directed more posteriorly than ventrally, and subtriangular in outline.

368

369 The neural canal is very small compared to the centrum, being only about $1 / 5$ as high as the

370 latter. The width and height of the anterior opening are approximately equal, whereas the

371 posterior opening is only two thirds as wide as high. The neural arch is restricted to the anterior

372 half of the centrum as in the middle caudal vertebrae of Phuwiangosaurus (Martin et al. 1999:

373 Fig. 26) and most other titanosauriforms (Upchurch 1998). In Gobititan the neural arch is placed

374 near the mid-length of the centrum in the mid-caudals, but is entirely restricted to the anterior

375 part of the centrum in caudal 33 (You, Tang \& Luo 2003). The neural spine and zygapophyses

376 are broken away, although the base of the left prezygapophysis is partially preserved. The

377 prezygapophysis appears to have originally extended anterodorsally, and has a transversely

378 convex ventral surface. The damaged surfaces of the neural arch are honeycombed with 
379 pneumatic chambers in a camellate pattern, as in an anterior caudal of the titanosaurian

380 Malawisaurus (Wedel 2009).

381

382

383

384

Humerus. Two well-preserved partial humeri of different sizes (ZGT56-60 and ZGT089) are

385

386

387

present in the sample (Fig. 6). ZGT56-60 is the larger and more completely preserved of the two.

Measurements for these two humeri are given in Table 2.

388

389

390

391

392

393

394

395

396

397

398

399

400

401

402

403

404

405

406

407

408

409

410

411

412

413

414

ZGT56-60 is the proximal half of a right humerus, and is slightly compressed anteroposteriorly.

The long axis of this partial humerus appears straight in lateral view, and the proximal end is transversely wide. Although the distal end is absent, the preserved portion of the humerus extends more or less to the midshaft region, and indicates that the humerus as a whole was robust.

The proximal end of the humerus is extremely expanded transversely, its width of $40 \mathrm{~cm}$ being about double that of the distalmost preserved part of the humeral shaft. The head of the humerus is proximally convex and forms a strong medial prominence as in other sauropods (Upchurch, Barrett \& Dodson 2004). The proximolateral corner is relatively rounded, and subdued relative to the proximal apex of the humeral head, as in the basal titanosauriform Qingxiusaurus (Mo et al., 2008: Fig. 1). By contrast, the proximolateral corner has a well-defined square outline in most somphospondylans (Upchurch, Barrett \& Dodson 2004). The medial part of the proximal articular surface is slightly convex in anterior view, and the articular surface as a whole does not show the sigmoid curvature that is present in some titanosaurians, such as Diamantinasaurus (Poropat et al. 2015) and Opisthocoelicaudia (Borsuk-Białynicka 1977). The proximal articular surface is rugose, crescent-shaped, and unevenly expanded anteroposteriorly to form the humeral head, the greatest expansion occurring around the mediolateral midpoint of the proximal surface. This is unlike the anteroposteriorly narrow humeral head in Euhelopus (Young 1935; Wilson \& Unchurch 2009). The medial end of the proximal articular surface tapers gradually to a point, whereas approximately the lateralmost third of the proximal surface has a subrectangular outline, is distinctly narrower than the expanded humeral head, and slopes down gently towards the deltopectoral crest. No fossae or tubercles interrupt the proximal articular surface. The convex humeral head is only moderately well-developed and merges gradually into the rest of the proximal end of the humerus. In some macronarian taxa, such as Haestasaurus (Upchurch, Mannion \& Taylor 2015), the humeral head is more prominent and sharply defined. Well distal to the proximal articular surface, a bulge is present on the lateral side of the humerus posterior to the deltopectoral crest. A scar or eminence in this area occurs in a variety of titanosauriforms and is conventionally identified as marking the insertion of M. scapulohumeralis anterior (Borsuk- 
415 Białynicka 1977; Upchurch et al. 2015). The bulge is prominent and clearly visible in anterior

416 view, as in taxa such as Qingxiusaurus (Mo et al. 2008) and Neuquensaurus (Otero 2010).

417

418 The deltopectoral crest is situated along the anterolateral margin of the humerus and extends to

419 the distal part of the preserved portion. The crest is low, straight, and thickened mediolaterally in

420 its midlength portion. This is unlike the strongly medially directed deltopectoral crest seen in the

421 titanosaurs Opisthocoelicaudia (Borsuk-Białynicka 1977) and Zhuchengtitan (Mo et al. 2018).

422 The deltopectoral crest is a subdued structure with a flattened anterior surface, unlike the more

423 prominent and ridge-like deltopectoral crest of Qingxiusaurus (Mo et al. 2008: Fig. 1). In

424 anterior or posterior view the lateral margin of the shaft appears relatively straight in ZGT56-60

425 but concave in the small humerus ZGT089, a variation that may reflect ontogenetic change. A

426 straight lateral humeral margin has been regarded as a derived feature only seen in some

427 titanosauriforms, such as Malawisaurus (Gomani 2005).

428

429 The proximal part of the cranial surface is mediolaterally concave, and is cracked due to poor

430 preservation. No rugosities are apparent on this part of the humeral surface. The posterior surface

431 is convex, giving the cross-section of this part of the humerus a thin, crescentic shape. In

432 ZGT56-60, the cross-section of the middle part of the shaft is three times as mediolaterally wide

433 as anteroposteriorly thick, but in ZGT089 the cross-section is oval and only slightly wider than

434 thick (Fig. 6). The extreme midshaft thinness of ZGT56-60 may be a result of the compression

435 that caused the cracks on the anterior surface.

436

437 Ischium. The left ischium ZMW148 is well-preserved and nearly complete (Fig. 7), and is

438 flattened, anteroposteriorly wide, and dorsoventrally elongate. The medial surface remains

439 obscured by matrix. A 3D model has been prepared for detailed examination and comparison.

440 The ischium has a dorsoventral length of $59.5 \mathrm{~cm}$ (Table 3) and is characterized by a short,

441 robust iliac peduncle, a wide, elongate pubic peduncle, and a slender, rod-like posteroventral

442 shaft. The maximum width of the middle portion of the ischium is more than twice that of the

443 iliac peduncle or the distal shaft.

444

445 The iliac peduncle accounts for about one-fourth of the proximodistal length of the ischium, and

446 contributes a large portion to the margin of the acetabulum. The articular surface for the ilium

447 faces anterolaterally, while the iliac peduncle as a whole thickens posteriorly and therefore has a

448 subtriangular cross-section. The anterior margin of the iliac peduncle is continuous with the

449 dorsal margin of the pubic peduncle. The iliac peduncle has a relatively thin stalk but is

450 transversely expanded at the dorsal end for the articulation with the ilium. The acetabular surface 
451 of the ischium is mediolaterally narrowest in its central portion (Fig. 7C), which occurs in most 452 rebbachisaurids (Mannion et al. 2012) but has also been reported in the titanosauriform

453 Huabeisaurus from the Upper Cretaceous of Shanxi Province, China (D'Emic et al. 2013: Fig. 454 20).

455

456

457

458

459

460

461

462

463

464

465

466

467

468

469

470

471

472

473

474

475

476

477

478

479

480

481

482

483

484

485

486

The concave posterior margin of the ischium is thickened, forming a prominent ridge that extends from the base of the iliac peduncle to the posteroventral end of the ischial shaft (Fig. 7A). This ridge is damaged in the mid-region of the posterior margin (see 3D model). A similar ridge is also seen in the brachiosaurid Soriatitan (Royo-Torres et al. 2017: Fig. 9). There is no ischial tuberosity on the lateral surface of the ischium, unlike the condition in Huabeisaurus (D'Emic et al. 2013) and Neuquensaurus australis (see Otero 2010: Fig. 8A-B).

The pubic peduncle is mediolaterally thin and has a flat lateral surface. Its anterior margin has an irregular appearance resulting from damage. The dorsoventral height of the pubic peduncle is about triple its anteroposterior length, as in the titanosauriforms Sonidosaurus (Xu et al. 2006) and Qiaowanlong (You \& Li 2009: Fig. 3). The ventral margin of the ischium is thin and somewhat damaged.

The length of the posteroventral shaft is slightly less than the dorsoventral height of the ischial peduncle. The posterior edge of the shaft is transversely expanded and rounded whereas the anterior edge is thin and sheet-like, so that the shaft has a subtriangular cross-section. The shaft is extremely narrow anteroposteriorly, in contrast to the wide shaft seen in most titanosauriforms, such as Huabeisaurus (D'Emic et al. 2013), Qiaowanlong (You \& Li 2009: Fig. 3), Sonidosaurus (Xu et al. 2006) and Rapetosaurus (Curry Rogers 2009: Fig. 41). However, an ischium with a narrow distal shaft also occurs in some titanosauriforms, such as Dongyangsaurus (Lü et al. 2008, Plate II), Opisthocoelicaudia and an unnamed Brazilian taxon (Lehman \& Coulson 2002), as well as in most rebbachisaurids including Comahuesaurus (Carballido et al. 2012: Fig. 10), Zapalasaurus (Salgado et al. 2006: Fig. 6) and Rebbachisaurus (Wilson \& Allain 2015: Fig. 15). The distal end of the shaft is unexpanded, as in the brachiosaurid Soriatitan (Royo-Torres et al. 2017) and such rebbachisaurids as Comahuesaurus, Zapalasaurus (Salgado et al. 2006; Carballido et al. 2012). In most titanosauriforms, by contrast, including Qiaowalong (You \& Li 2009) and Huabeisaurus (D'Emic et al. 2013), the distal end of the shaft is anteroposteriorly expanded. The anteroposterior length of the distal end is only twice the mediolateral width, compared to three times the width in Sonidosaurus (Xu et al. 2006) and five times the width in Huabeisaurus (D'Emic et al. 2013). 
487 In general, the ischium is similar to those of other titanosauriforms, especially in having a 488 dorsoventrally elongate pubic peduncle. However, the ischium is also unusual in having some 489 features that are otherwise mainly known in rebbachisaurids, including a slender shaft and a 490 narrow central portion of the acetabular surface.

491

Fibula. The long and slender right fibula ZMW 51-57 is well-preserved, except that part of the 493 midshaft region is missing (Fig. 8). Measurements of the fibula are provided in Table 3. In lateral view, the anterior margin of the fibula is relatively straight, whereas the posterior margin is

495

496

497

498

499

500

501

502

503

504

505

506

507

508

509

510

511

512

513

514

515 Ungual. A well-preserved, nearly complete large pedal ungual (ZMW013), with a length of

516

517

518

519

520

521

522 strongly concave. The proximal end is transversely compressed and flares asymmetrically in lateral view, being expanded posteriorly but not anteriorly. The proximal end has a crescentic outline, being convex laterally and concave medially, and the posterior part of the proximal end is thicker than the anterior part. Additionally, the proximal end lacks the anteromedial crest, which fits into a notch on the tibia, seen in such titanosauriforms as Gobititan (You et al. 2003: Fig. 2), Erketu (Ksepka and Norell 2006: Fig. 10) and Euhelopus (Wilson et al. 2009: Fig. 25)

The anteroproximal portion of the fibula appears rounded in lateral view. The strong posterior expansion of the proximalmost part of the fibula has a subtriangular outline in lateral view, although the posterior apex is truncated (Fig. 8A). The lateral surface of the shaft remains strongly convex over the entire length of the fibula, whereas the medial surface is concave over the proximal half of the bone but slightly convex over the distal half.

A lateral trochanter is present near the midpoint of the shaft. The trochanter is slightly curved and anterodorsally oriented, and takes the form of two elongate, narrow parallel ridges as observed in many titanosauriforms, such as Huabeisaurus (D'Emic et al. 2013: Fig. 23). Deep fossae are present both anterior and posterior to the more posterior of the two ridges. The distal end of the fibula is expanded relative to the midshaft, strongly convex both anteroposteriorly and transversely, and lenticular in outline.

about $10 \mathrm{~cm}$, is present. This element is strongly compressed laterally, with slightly dorsoventrally convex lateral and medial sides, as in other Eusauropoda (Wilson \& Sereno 1998). The proximal end of the ungual is dorsoventrally deep, transversely narrow, and symmetrical in outline. The dorsal margin of the ungual is sharp and curved anteroventrally, whereas the ventral surface is transversely expanded and flattened (Fig. 8I). Which pedal digit the ungual belongs to is uncertain. 


\section{Discussion}

524 Titanosauriforms are relatively diverse and abundant in the Cretaceous of eastern Asia, at least

52520 species having been erected (D'Emic et al. 2013; Mo et al., 2016; Averianov \& Skutschas

526 2017; Averianov et al. 2018). Wilson (2005) noted that all Cretaceous sauropods from eastern

527 Asia are titanosauriforms, whereas all Jurassic sauropods from the region are non-neosauropods.

528 The Zhuzhou sauropod specimens add to this wealth of fossil evidence regarding Cretaceous

529 eastern Asian titanosauriforms, and collectively display an interesting and complex combination

530 of morphological characters.

531

532 Many authors have suggested some degree of endemicity among eastern Asian sauropods in 533 general, and have proposed the existence of putative endemic eastern Asian titanosauriform 534 clades including Euhelopodidae (Wilson \& Upchurch 2009; D’Emic, 2012), Nemegtosauridae

535 (Wilson 2005) and Opisthocoelicaudiinae (You et al. 2004). Recent phylogenies support the 536 validity of Euhelopodidae, but the validity of Nemegtosauridae and Opisthocoelicaudiinae 537 remains controversial (Upchurch, Mannion \& Taylor 2015; Poropat et al. 2016; González Riga et 538 al. 2018; Mannion et al., 2019). Arriving at a clearer understanding of titanosauriform phylogeny 539 will undoubtedly require more extensive description of some of the lesser-studied Cretaceous 540 eastern Asia taxa, ideally based in some cases on much more complete specimens than are 541 presently available. In this connection, the Zhuzhou sauropod material is unfortunately so 542 fragmentary that it is difficult to establish its phylogenetic position within Titanosauriformes, or 543 even to determine whether more than one taxon might be present in the sample. Nevertheless, 544 some if not all of the Zhuzhou sauropod bones are clearly of somphospondylan origin.

545 Somphospondylans were among the most abundant and widespread sauropods, and were 546 particularly diverse in Asia during the Barremian (Poropat et al., 2016). Recent evidence

547 indicates, however, that the basal somphospondylan Euhelopus could be as early as Berriasian

548 and accordingly could represent the oldest known somphospondylan, suggesting that

549 somphospondylans could have originated in eastern Asia (Xu \& Li, 2015).

550

551 Titanosauria, defined as the least inclusive clade containing both Andesaurus delgadoi and 552 Saltasaurus loricatus, originated in the Early Cretaceous (Mannion et al. 2013). The oldest 553 known valid titanosaurians include Tapuiasaurus from the Aptian of Brazil (Zaher et al. 2011), 554 Malawisaurus and Karogasaurus from the Aptian of Africa (Gomani 2005), Daxiatitan and 555 Yongjinglong from the Early Cretaceous of China (You et al. 2008; Li et al. 2014), and 556 Tengrisaurus from the Barremian-Aptian Murtoi Formation of south-central Siberia, Russia 557 (Averianov \& Skutschas 2017). A South American origin has been inferred for Titanosauria 
558 using a model-based phylogenetic approach (Gorscak \& O'Connor 2016). However, the analysis

559 in question was carried out before Tengrisaurus, which likely represents the earliest titanosaurian 560 from Asia, was reported. Considering the Asian provenance of Tengrisaurus and the fact that

561 many of the early titanosaurians mentioned above are also from Asia, it seems possible that

562 titanosaurians originated in Asia and subsequently formed endemic groupings in various parts of

563 the world as the continents moved apart during the Cretaceous. It is unclear, however, whether

564 any of the Zhuzhou specimens represent titanosaurians as opposed to basal titanosauriforms.

565

566 Some of the Zhuzhou sauropod specimens display an intriguing combination of characters

567 typically seen in basal sauropods, diplodocoids and titanosauriforms. For example, pneumatic

568 fossae and a sharp keel are present on the ventral surface of the probable anterior cervical

569 ZGT002. Similar features are otherwise known mainly in rebbachisaurids and dicraeosaurids

570 (Whitlock, D’Emic \& Wilson 2011; Ibiricu et al. 2013; Tschopp, Mateus \& Benson 2015),

571 although they also occur in the anterior cervical vertebrae of the basal sauropod Shunosaurus

572 (Dong, Zhou \& Zhang 1983). The ischium ZMW148 has a relatively slender posteroventral shaft

573 and an acetabular surface that is narrowest in its central portion, as in the ischia of most

574 diplodocoids (Mannion et al. 2012; Wilson \& Allain 2015). The presence of diplodocoid traits in

575 some of the Zhuzhou specimens suggests that patterns of character evolution in neosauropods

576 were more complex than previously appreciated, reduces the sharpness of the distinction in

577 skeletal anatomy between titanosauriforms and diplodocoids, and reinforces the need for caution

578 in referring incomplete specimens to one clade or the other. In particular, diplodocoids are

579 currently represented in the Asian fossil record only by the recently discovered dicraeosaurid

580 Lingwulong from the Toarcian-Bajocian of Ningxia Autonomous Region in northern China.

581 Various specimens from the Cretaceous of Asia have been previously suggested to also represent

582 diplodocoids, but have been placed in or near Titanosauriformes in recent phylogenetic analyses;

583 this applies, for example, to the holotype of Nemegtosaurus from the Upper Cretaceous of

584 Mongolia (Wilson 2005), and to an isolated anterior caudal vertebra from the Lower Cretaceous

585 of Shandong Province, China (Upchurch \& Mannion 2009; Whitlock, D’Emic \& Wilson 2011).

586 At present, the absence of diplodocoids from the Cretaceous of Asia is a clear

587 palaeobiogeographic datum, and the occurrence of a few typically diplodocoid characters among

588 the Zhuzhou sample of titanosauriform material implies that future claims of diplodocoid

589 occurrences in the Cretaceous of Asia should be treated with skepticism unless they are based on

590 more substantial evidence than a small number of features occurring in a fragmentary specimen.

591

\section{Conclusions}


593 This contribution represents the first detailed study of sauropod material from the Upper

594 Cretaceous Daijiaping Formation of Tianyuan District, Zhuzhou City, Hunan Province, southern

595 China. Most of the individual bones are clearly referable to Titanosauriformes, and therefore

596 document a new occurrence of this clade in the Upper Cretaceous of eastern Asia. While none of

597 the specimens are demonstrably of non-titanosauriform origin, some possess features that occur

598 in basal sauropods and diplodocoids, suggesting complex patterns of character evolution within

599 Neosauropoda.

600

\section{Acknowledgements}

602 We thank Zhenhua Xiao and Dachun Wang of the Zhuzhou Land Resource Bureau, and Daohe

603 Xi, Yalan Liu and Jun Lei of the Zhuzhou Museum, for their hospitality, and Paul Upchurch for

604 his constructive comments on the possible affinities of the specimens described in this paper. We

605 thank Philip Mannion and Stephen Poropat for their detailed reviews of a previous version of this

606 paper and Graciela Piñeiro for her constructive suggestions. We thank the editor Hans-Dieter

607 Sues, the reviewers John Whitlock and Alexander Averianov for their useful comments on

608 improving the manuscript.

609

610

\section{References}

611

612

613

614

615

616

617

618

619

620

621

622

623

624

625

626

627

628
Averianov A, and Skutschas P. 2017. A new lithostrotian titanosaur (Dinosauria, Sauropoda) from the Early Cretaceous of Transbaikalia, Russia. Biological Communications 62:6-18. DOI: 10.21638/11701/spbu03.2017.102

Averianov A, Ivantsov S, Skutschas P, Faingertz A, and Leshchinskiy S. 2018. A new sauropod dinosaur from the Lower Cretaceous Ilek Formation, Western Siberia, Russia. Geobios 51:1-14. DOI: 10.1016/j.geobios.2017.12.004

Azuma Y, and Shibata M. 2010. Fukuititan nipponensis, a new titanosauriform sauropod from the Early Cretaceous Tetori Group of Fukui Prefecture, Japan. Acta Geologica Sinica - English Edition 84:454-462. DOI: 10.1111/j.1755-6724.2010.00268.x

Borsuk-Białynicka M. 1977. A new camarasaurid sauropod Opisthocoelicaudia skarzynskii gen. n., sp. n. from the Upper Cretaceous of Mongolia. Palaeontologia Polonica 37:5-64.

Carballido JL, Salgado L, Pol D, Canudo JI, and Garrido A. 2012. A new basal rebbachisaurid (Sauropoda, Diplodocoidea) from the Early Cretaceous of the Neuquén Basin; evolution and biogeography of the group. Historical Biology 24:631-654. DOI: 10.1080/08912963.2012.672416

Carballido JL, and Sander PM. 2014. Postcranial axial skeleton of Europasaurus holgeri (Dinosauria, Sauropoda) from the Upper Jurassic of Germany: implications for sauropod ontogeny and phylogenetic relationships of basal Macronaria. Journal of Systematic Palaeontology 12:335387. DOI: 10.1080/14772019.2013.764935

PeerJ reviewing PDF | (2019:08:40330:1:1:NEW 3 Nov 2019) 
629 Coria RA, Filippi LS, Chiappe LM, Garcia R, and Arcucci AB. 2013. Overosaurus paradasorum gen. et

630

631

632

633

634

635

636

637

638

639

640

641

642

643

644

645

646

647

648

649

650

651

652

653

654

655

656

657

658

659

660

661

662

663

664

665

666

667

668

669 sp. nov., a new sauropod dinosaur (Titanosauria: Lithostrotia) from the Late Cretaceous of Neuquén, Patagonia, Argentina. Zootaxa 3683:357-376. DOI: 10.11646/zootaxa.3683.4.2

Curry Rogers K. 2009. The postcranial osteology of Rapetosaurus krausei (Sauropoda: Titanosauria) from the Late Cretaceous of Madagascar. Journal of Vertebrate Paleontology 29:1046-1086. DOI: $10.1671 / 039.029 .0432$

D'emic MD. 2012. The early evolution of titanosauriform sauropod dinosaurs. Zoological Journal of the Linnean Society 166:624-671. DOI: 10.1111/j.1096-3642.2012.00853.x

D'Emic MD, Mannion PD, Upchurch P, Benson RBJ, Pang Q, and Cheng Z. 2013. Osteology of Huabeisaurus allocotus (Sauropoda: Titanosauriformes) from the Upper Cretaceous of China. PLOS ONE 8:e69375. DOI:10.1371/journal.pone.0069375

Dong Z, Zhou S, and Zhang Y. 1983. Dinosaurs from the Jurassic of Sichuan. Beijing: Science Press.

Fanti F, Cau A, Cantelli L, Hassine M, and Auditore M. 2015. New information on Tataouinea hannibalis from the Early Cretaceous of Tunisia and implications for the tempo and mode of rebbachisaurid sauropod evolution. PLOS ONE 10:e0123475. DOI: 10.1371/journal.pone. 0123475

Goloboff PA, and Catalano SA. 2016. TNT version 1.5, including a full implementation of phylogenetic morphometrics. Cladistics 32:221-238. DOI: 10.1111/cla.12160

Gomani EM. 2005. Sauropod dinosaurs from the Early Cretaceous of Malawi, Africa. Palaeontologia Electronica 8:27A: 21-37.

González Riga BJ, Mannion PD, Poropat SF, Ortiz David LD, and Coria JP. 2018. Osteology of the Late Cretaceous Argentinean sauropod dinosaur Mendozasaurus neguyelap: implications for basal titanosaur relationships. Zoological Journal of the Linnean Society 184:136-181. DOI: 10.1093/zoolinnean/zlx103

Gorscak E, and O'Connor PM. 2016. Time-calibrated models support congruency between Cretaceous continental rifting and titanosaurian evolutionary history. Biology Letters 12:20151047. DOI: 10.1098/rsbl.2015.1047

Gorscak E, O'Connor PM, Stevens NJ, and Roberts EM. 2014. The basal titanosaurian Rukwatitan bisepultus (Dinosauria, Sauropoda) from the middle Cretaceous Galula Formation, Rukwa Rift Basin, southwestern Tanzania. Journal of Vertebrate Paleontology 34:1133-1154. DOI: $10.1080 / 02724634.2014 .845568$

Han F, Xing H, Tong Q, Sullivan C, Xu X, Wu R, Hu N, and Tong G. 2017. Preliminary study of a diverse dinosaur assemblage from the Upper Cretaceous of Zhuzhou, Hunan Province. Acta Palaeontologica Sinica 56:1-9. (in Chinese with English abstract)

Harris JD. 2006. The axial skeleton of the dinosaur Suuwassea emilieae (sauropoda: Flagellicaudata) from the Upper Jurassic Morrison Formation of Montana, USA. Palaeontology 49:1091-1121. Doi:10.1111/j.1475-4983.2006.00577.x

Ibiricu L, Casal G, Martínez R, Lamanna M, Luna M, and Salgado L. 2013. Katepensaurus goicoecheai, gen. et sp. nov., a Late Cretaceous rebbachisaurid (Sauropoda, Diplodocoidea) from central Patagonia, Argentina. Journal of Vertebrate Paleontology 33:1351-1366. DOI: $10.1080 / 02724634.2013 .776562$ 
670 Ksepka DT, and Norell MA. 2006. Erketu ellisoni, a Long-necked Sauropod from Bor Guvé (Dornogov

671

672

673

674

675

676

677

678

679

680

681

682

683

684

685

686

687

688

689

690

691

692

693

694

695

696

697

698

699

700

701

702

703

704

705

706

707

708

Aimag, Mongolia). American Museum Novitates:1-16. DOI: 10.1206/00030082(2006)3508[1:EEALSF]2.0.CO;2

Li L, Li D, You H, and Dodson P. 2014. A new titanosaurian sauropod from the Hekou Group (Lower Cretaceous) of the Lanzhou-Minhe Basin, Gansu Province, China. PLOS ONE 9:e85979. DOI: 10.1371/journal.pone.0085979

Lü J, Xu L, Pu H, Zhang X, Zhang Y, Jia S, Chang H, Zhang J, and Wei X. 2013a. A new sauropod dinosaur (Dinosauria, Sauropoda) from the late Early Cretaceous of the Ruyang Basin (central China). Cretaceous Research 44:202-213. DOI: 10.1016/j.cretres.2013.04.009

Lü J, Xu L, Zhang X, Hu W, Wu Y, Jia S, and Ji Q. 2007. A new gigantic sauropod dinosaur with the deepest known body cavity from the Cretaceous of Asia. Acta Geologica Sinica - English Edition 81:167-176. DOI: 10.1111/j.1755-6724.2007.tb00941.x

Lü J, Yi L, Zhong H, and Wei X. 2013b. A new somphospondylan sauropod (Dinosauria, Titanosauriformes) from the Late Cretaceous of Ganzhou, Jiangxi Province of southern China. Acta Geologica Sinica 87:678-685. DOI: 10.1111/1755-6724.12079

Lü J, Yoichi A, Cheng R, Zheng W, and Jin X. 2008. A new titanosauriform sauropod from the early Late Cretaceous of Dongyang, Zhejiang Province. Acta Geologica Sinica 82:225-235. DOI: 10.1111/j.1755-6724.2008.tb00572.x

Lehman TM, and Coulson AB. 2002. A juvenile specimen of the sauropod dinosaur Alamosaurus sanjuanensis from the Upper Cretaceous of Big Bend National Park, Texas. Journal of Paleontology 76:156-172. DOI: 10.1017/S0022336000017431

Mannion PD, and Calvo JO. 2011. Anatomy of the basal titanosaur (Dinosauria, Sauropoda) Andesaurus delgadoi from the mid-Cretaceous (Albian-early Cenomanian) Río Limay Formation, Neuquén Province, Argentina: implications for titanosaur systematics. Zoological Journal of the Linnean Society 163:155-181. DOI: 10.1111/j.1096-3642.2011.00699.x

Mannion PD, Upchurch P, Barnes RN, and Mateus O. 2013. Osteology of the Late Jurassic Portuguese sauropod dinosaur Lusotitan atalaiensis (Macronaria) and the evolutionary history of basal titanosauriforms. Zoological Journal of the Linnean Society 168:98-206. DOI: 10.1111/zoj.12029

Mannion PD, Upchurch P, Mateus O, Barnes RN, and Jones ME. 2012. New information on the anatomy and systematic position of Dinheirosaurus lourinhanensis (Sauropoda: Diplodocoidea) from the Late Jurassic of Portugal, with a review of European diplodocoids. Journal of Systematic Palaeontology 10:521-551. DOI: 10.1080/14772019.2011.595432

Mannion PD, Upchurch P, Schwarz D, and Wings O. 2019. Taxonomic affinities of the putative titanosaurs from the Late Jurassic Tendaguru Formation of Tanzania: phylogenetic and biogeographic implications for eusauropod dinosaur evolution. Zoological Journal of the Linnean Society 185:784-909. DOI: 10.1093/zoolinnean/zly068

Martin V. 1999. Description of the type and referred material of Phuwiangosaurus sirindhornae Martin, Buffetaut and Suteethorn, 1994, a sauropod from the Lower Cretaceous of Thailand. Oryctos 2:39-91.

Peer] reviewing PDF | (2019:08:40330:1:1:NEW 3 Nov 2019) 
709

710

711

712

713

714

715

716

717

718

719

720

721

722

723

724

725

726

727

728

729

730

731

732

733

734

735

736

737

738

739

740

741

742

743

744

745

746

747

748

749

Mo JY, Huang CL, Zhao ZR, Wang W, and Xu X. 2008. A new titanosaur (Dinosauria: Sauropoda) from the Late Cretaceous of Guangxi, China. Vertebrata Palasiatica 46:147-156. (in Chinese with English abstract)

Mo JY, Wang KB, Chen SQ, Wang PY, and Xu X. 2017. A new titanosaurian sauropod from the Late Cretaceous strata of Shandong Province. Geological Bulletin of China 36:1501-1505. (In Chinese with English abstract)

Otero A. 2010. The appendicular skeleton of Neuquensaurus, a Late Cretaceous saltasaurine sauropod from Patagonia, Argentina. Acta Palaeontologica Polonica 55:399-426. DOI: 10.4202/app.2009.0099

Pang Q, and Cheng Z. 2000. A new family of sauropod dinosaur from the Upper Cretaceous of Tianzhen, Shanxi Province, China. Acta Geologica Sinica 74:117-125. DOI: 10.1111/j.17556724.2000.tb00438.x

Pol D, and Escapa IH. 2010. Unstable taxa in cladistic analysis: identification and the assessment of relevant characters. Cladistics 25:515-527. DOI: 10.1111/j.1096-0031.2009.00258.x

Poropat SF, Mannion PD, Upchurch P, Hocknull SA, Kear BP, Kundrát M, Tischler TR, Sloan T, Sinapius GH, and Elliott JA. 2016. New Australian sauropods shed light on Cretaceous dinosaur palaeobiogeography. Scientific Reports 6:34467. DOI: 10.1038/srep34467

Poropat SF, Upchurch P, Mannion PD, Hocknull SA, Kear BP, Sloan T, Sinapius GHK, and Elliott DA. 2015. Revision of the sauropod dinosaur Diamantinasaurus matildae Hocknull et al. 2009 from the mid-Cretaceous of Australia: Implications for Gondwanan titanosauriform dispersal. Gondwana Research 27:995-1033. DOI: 10.1016/j.gr.2014.03.014

Royo-Torres R, Fuentes C, Meijide M, Meijide-Fuentes F, and Meijide-Fuentes M. 2017. A new Brachiosauridae Sauropod dinosaur from the lower Cretaceous of Europe (Soria Province, Spain). Cretaceous Research 80:38-55. DOI: 10.1016/j.cretres.2017.08.012

Saegusa H, and Ikeda T. 2014. A new titanosauriform sauropod (Dinosauria: Saurischia) from the Lower Cretaceous of Hyogo, Japan. 2014 3848:1-66. DOI: 10.11646/zootaxa.3848.1.1

Salgado L, Carvalho IdS, and Garrido AC. 2006. Zapalasaurus bonapartei, a new sauropod dinosaur from La Amarga Formation (Lower Cretaceous), northwestern Patagonia, Neuquén Province, Argentina. Geobios 39:695-707. DOI: 10.1016/j.geobios.2005.06.001

Tang F, Kang XM, Jin XS, Wei F, and Wu WT. 2001. A new sauropod dinosaur of Cretaceous from Jiangshan, Zhejiang Province. Vertebrata PalAsiatica 39:277-282. (In Chinese with English abstract)

Tschopp E, and Mateus O. 2013. The skull and neck of a new flagellicaudatan sauropod from the Morrison Formation and its implication for the evolution and ontogeny of diplodocid dinosaurs. Journal of Systematic Palaeontology 11:853-888. DOI: 10.1080/14772019.2012.746589

Tschopp E, Mateus O, and Benson RB. 2015. A specimen-level phylogenetic analysis and taxonomic revision of Diplodocidae (Dinosauria, Sauropoda). PeerJ 3:e857. DOI: 10.7717/peerj.857 Upchurch P. 1998. The phylogenetic relationships of sauropod dinosaurs. Zoological Journal of the Linnean Society 124:43-103. DOI: 10.1111/j.1096-3642.1998.tb00569.x

Upchurch P, Barrett PM, and Dodson P. 2004. Sauropoda. In: Weishampel DB, Peter D, and Osmólska H, eds. The Dinosauria (second edition). Berkeley: University of California Press, 259-322.

Peer] reviewing PDF | (2019:08:40330:1:1:NEW 3 Nov 2019) 
750

751

752

753

754

755

756

757

758

759

760

761

762

763

764

765

766

767

768

769

770

771

772

773

774

775

776

777

778

779

780

781

782

783

784

785

786

787

788

789

790

Upchurch P, and Mannion P. 2009. The first diplodocid from Asia and its implications for the evolutionary history of sauropod dinosaurs. Palaeontology 52:1195-1207. DOI: $10.1111 / \mathrm{j} .1475-$ 4983.2009.00909.x

Upchurch P, Mannion PD, and Taylor MP. 2015. The anatomy and phylogenetic relationships of "Pelorosaurus" becklesii (Neosauropoda, Macronaria) from the Early Cretaceous of England. PLOS ONE 10:e0125819. DOI: 10.1371/journal.pone.0125819

Wang D, Cao X, Zhao H, Cao M, Fu G, Yan F, Qiang W, Wang Y. 2013. Discovery of Invertebrate Zoolite in the Xiaguan Formation of Xiaguan-Gaoqiu Basin, Henan, China, and its Importance for Stratigraphic Subdivision Comparison. Acta Geologica Sinica. 87:1049-1058

Wedel MJ. 2003. The evolution of vertebral pneumaticity in sauropod dinosaurs. Journal of Vertebrate Paleontology 23:344-357. DOI: 10.1671/0272-4634(2003)023[0344:TEOVPI]2.0.CO;2

Wedel MJ, Cifelli RL, and Sanders RK. 2000. Osteology, paleobiology, and relationships of the sauropod dinosaur Sauroposeidon. Acta Palaeontologica Polonica 45:343-388.

Wedel MJ, and Taylor MP. 2013. Neural spine bifurcation in sauropod dinosaurs of the Morrison Formation: ontogenetic and phylogenetic implications. PalArch's Journal of Vertebrate Palaeontology 10:1-34.

Wedel MJ. 2009. Evidence for bird-like air sacs in saurischian dinosaurs. Journal of Experimental Zoology Part A: Ecological Genetics and Physiology 311A:611-628. DOI: 10.1002/jez.513

Whitlock JA, D'Emic MD, and Wilson JA. 2011. Cretaceous diplodocids in Asia? Re-evaluating the phylogenetic affinities of a fragmentary specimen. Palaeontology 54:351-364. DOI: 10.1111/j.1475-4983.2010.01029.x

Wilson JA. 2005. Redescription of the Mongolian sauropod Nemegtosaurus mongoliensis Nowinski (Dinosauria: Saurischia) and comments on Late Cretaceous sauropod diversity. Journal of Systematic Palaeontology 3:283-318. DOI: 10.1017/S1477201905001628

Wilson JA, and Allain R. 2015. Osteology of Rebbachisaurus garasbae Lavocat, 1954, a diplodocoid (Dinosauria, Sauropoda) from the early Late Cretaceous-aged Kem Kem beds of southeastern Morocco. Journal of Vertebrate Paleontology 35:e1000701. DOI: 10.1080/02724634.2014.1000701

Wilson JA, and Sereno PC. 1998. Early evolution and higher-level phylogeny of sauropod dinosaurs. Journal of Vertebrate Paleontology 18:1-79. DOI: 10.1080/02724634.1998.10011115

Wilson JA, and Upchurch P. 2009. Redescription and reassessment of the phylogenetic affinities of Euhelopus zdanskyi (Dinosauria: Sauropoda) from the Early Cretaceous of China. Journal of Systematic Palaeontology 7:199-239. DOI: 10.1017/S1477201908002691

Xu J, and Li Z. 2015. Middle-Late Mesozoic sedimentary provenances of the Luxi and Jiaolai areas: Implications for tectonic evolution of the North China Block. Journal of Asian Earth Sciences 111:284-301. DOI: 10.1016/j.jseaes.2015.07.008

Xu X, Upchurch P, Mannion PD, Barrett PM, Regalado-Fernandez OR, Mo J, Ma J, and Liu H. 2018. A new Middle Jurassic diplodocoid suggests an earlier dispersal and diversification of sauropod dinosaurs. Nature Communications 9:2700. DOI: 10.1038/s41467-018-05128-1

Xu X, Zhang X, Tan Q, Zhao X, and Tan L. 2006. A new titanosaurian sauropod from Late Cretaceous of Nei Mongol, China. Acta Geologica Sinica 80:20-26. DOI: 10.1111/j.1755-6724.2006.tb00790.x 
791

792

793

794

795

796

797

798

799

800

801

802

803

804

805

806

807

808

809

810

811

812

813

814

815

816

817

You H, Li D, Zhou L, and Ji Q. 2008. Daxiatitan binglingi: a giant sauropod dinosaur from the Early Cretaceous of China. Gansu Geology 17:1-10. (In Chinese with English abstract)

You H, Qiang J, Lamanna MC, Li J, and Li Y. 2004. A titanosaurian sauropod dinosaur with opisthocoelous caudal vertebrae from the early Late Cretaceous of Liaoning Province, China. Acta Geologica Sinica 78:907-911. DOI: 10.1111/j.1755-6724.2004.tb00212.x

You H, Tang F, and Luo Z. 2003. A new basal titanosaur (dinosauria: Sauropoda) from the Early Cretaceous of China. Acta Geologica Sinica - English Edition 77:424-429. DOI: 10.1111/j.17556724.2003.tb00123.x

You H, and Li D. 2009. The first well-preserved Early Cretaceous brachiosaurid dinosaur in Asia. Proceedings Biological Sciences 276:4077-4082. DOI: 10.1098/rspb.2009.1278

Young CC, and Zhao X. 1972. Mamenchisaurus. Institute of Vertebrate Paleontology and Paleoanthropology Monograph Series A 8:1-30.

Young CC. 1935. Dinosaurian remains from Mengyin, Shantung. Bulletin of the Geological Society of China 14:519-533.

Yu Y, Jin X, Wu X, and Zhang Z. 2010. The epochs of dinosaurs and fossil eggs from Zhejiang Province. Geology in China 37:94-100.

Zaher H, Pol D, Carvalho AB, Nascimento PM, Riccomini C, Larson P, Juarez-Valieri R, PiresDomingues R, da Silva NJ, Jr., and de Almeida Campos D. 2011. A Complete Skull of an Early Cretaceous Sauropod and the Evolution of Advanced Titanosaurians. PLOS ONE 6:e16663. DOI: 10.1371/journal.pone.0016663

Zhang X, Lü J, Xu L, Li J, Yang L, Hu W, Jia S, Ji Q, and Zhang C. 2009. A new sauropod dinosaur from the Late Cretaceous Gaogou Formation of Nanyang, Henan Province. Acta Geologica Sinica (English Edition) 83:212-221. DOI: 10.1111/j.1755-6724.2009.00032.x

Zhu N, Xu Y, Wu R, Han F, Huang L, and Tong Q. 2019. The age and sedimentary environment of Late Cretaceous dinosaur fossils in the Tianyuan, Zhuzhou, Hunan. Earth Sciences. http://kns.cnki.net/kcms/detail/42.1874.p.20190323.1557.016.html:1-23. (In Chinese with English abstract)

Peer] reviewing PDF | (2019:08:40330:1:1:NEW 3 Nov 2019) 
Figure 1

Locality maps showing the site produced sauropod dinosaurs

(A) Map of China showing titanosauriform dinosaur localities, with Hunan Province shaded.

(B) Map of Hunan Province showing the location of Zhuzhou City. (C) Position of dinosaur locality adjacent to Lianhua Road, Tianyuan District, Zhuzhou City.
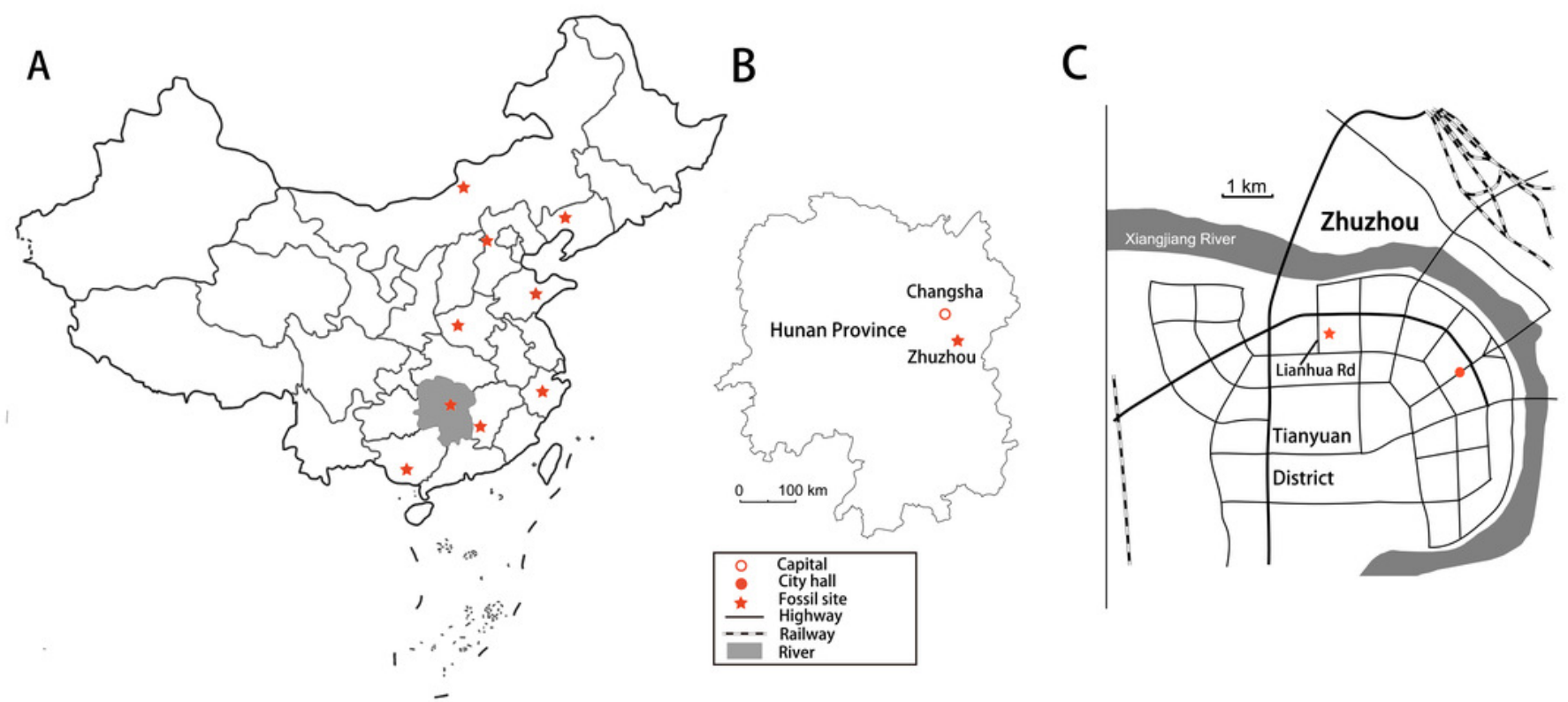
Figure 2

Stratigraphic section through the dinosaur-bearing Daijiaping Formation of Tianyuan District, Zhuzhou City.

Modified from Han et al. (2017). Abbreviations: $\mathbf{K}_{2}$, Late Cretaceous; Q, Quaternary. 


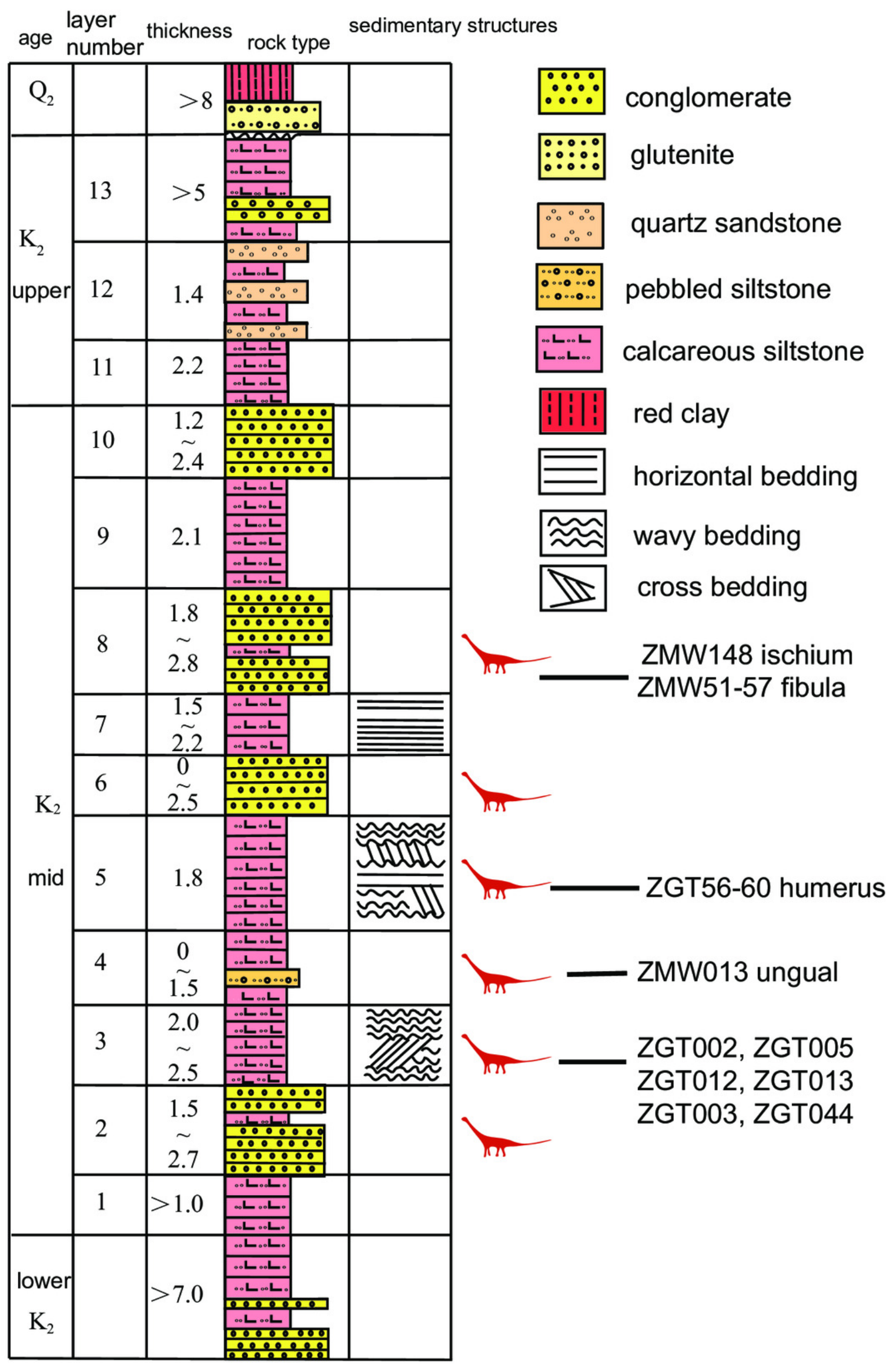




\section{Figure 3}

Cervical vertebra (ZGT002) of sauropod dinosaur from Zhuzhou City.

(A) ventrolateral view. (B) ventral view. (C) left dorsolateral view. (D) dorsal view. (E) anterior view. (F) posterior view. (G) right lateral view. Abbreviations :dp, diapophysis; fo, fossa; ipozf, infrapostzygapophyseal fossa;LCPOL, lateral centropostzygapophyseal lamina;Iprf, lateral fossa of the prezygapophyseal process;nc, neural canal;PCDL, posterior spinodiapophyseal lamina;PODL, postzygodiapophyseal lamina;pp, parapophysis; ppr, prominent posterodorsally oriented ridge; PRDL, prezygodiapophyseal lamina;SPRL, spinoprezygapophyseal lamina;SPOL, Spinopostzygapophyseal lamina; wvr, weak vertically oriented ridge. 

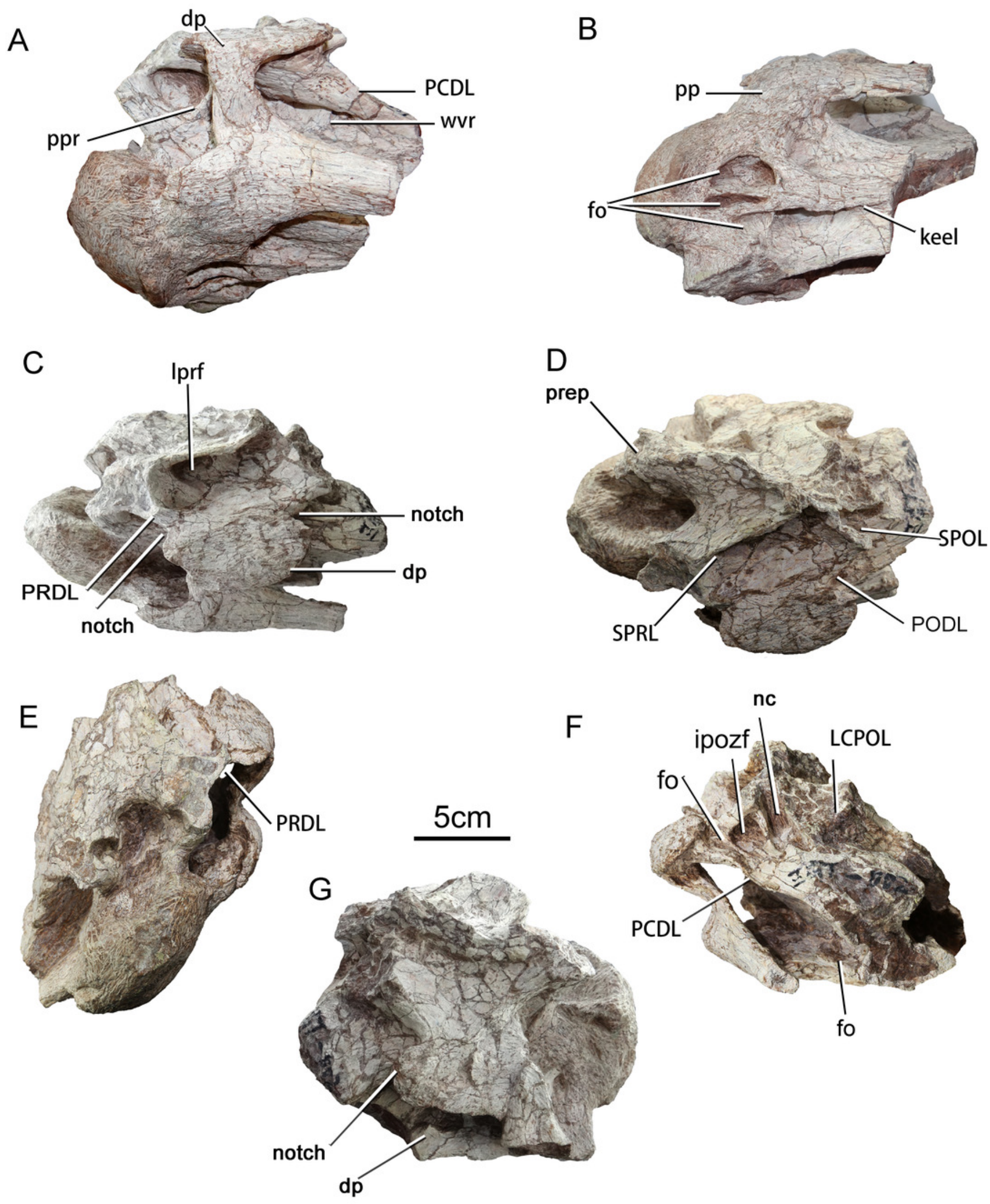


\section{Figure 4}

Cervical vertebra (ZGT012) and ribs of sauropod dinosaurs from Zhuzhou City.

(A-B) ZGT012, (A) centrum and associated rib in left lateral view; B, vertebra without rib in left lateral view and detached rib in medial view. (C-E) ZGT044, large posterior cervical rib. (C) dorsal view. (D) posterior view. (E) ventral view. (F-H) ZGT013, small posterior cervical rib. (F) dorsal view. (G) ventral view. (H) medial view. Abbreviations: fo, fossa; ppr, prominent posterodorsally oriented ridge; rid, ridge.

A

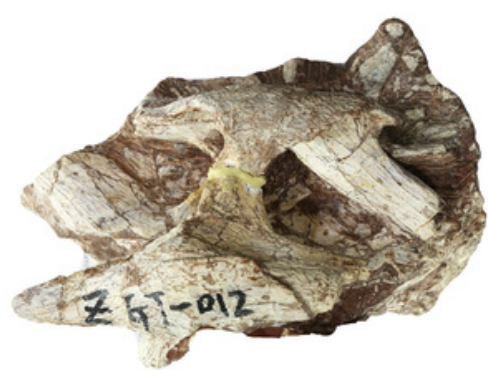

C

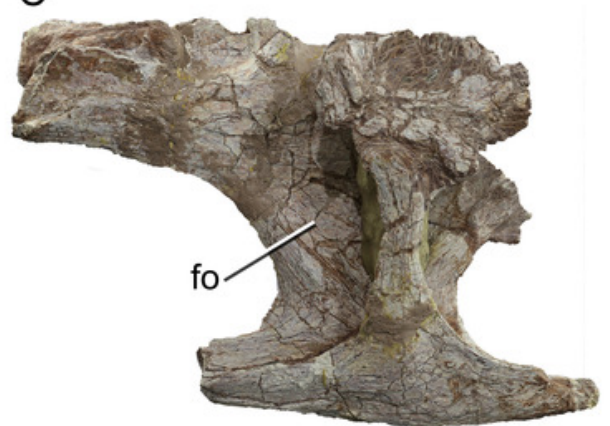

$\mathrm{F}$

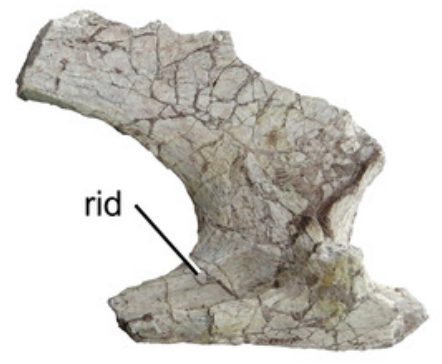

D

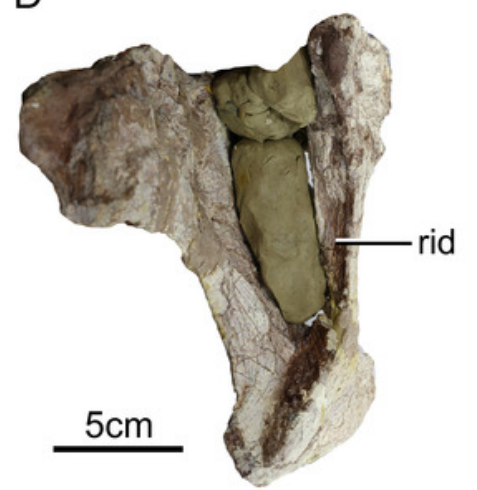

G

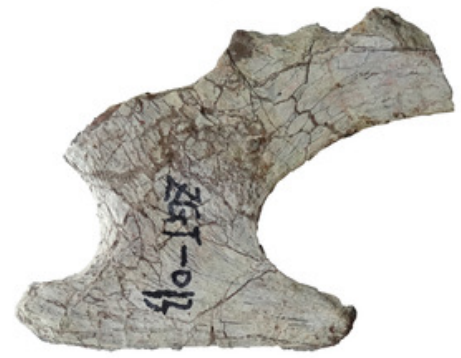

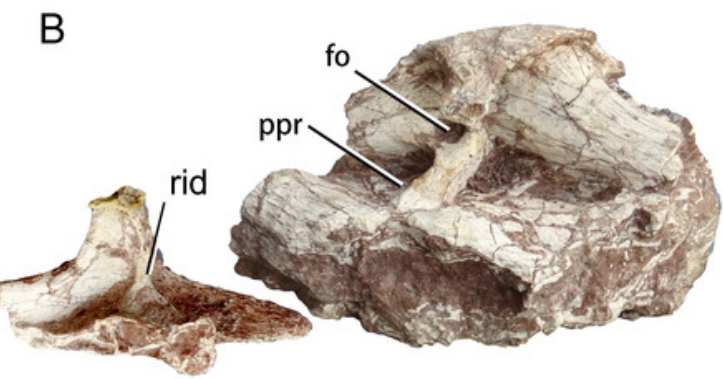

E

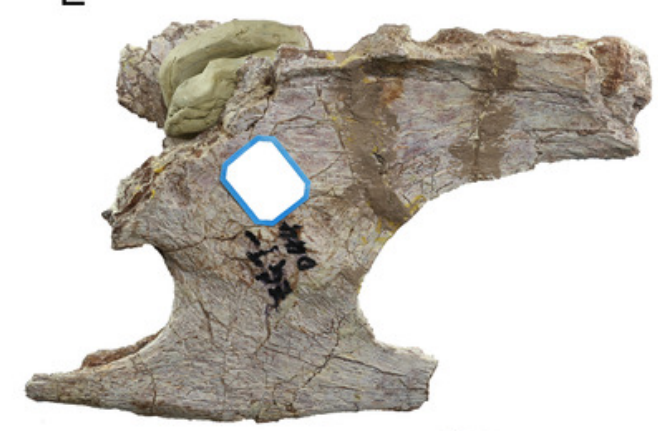

$\mathrm{H}$

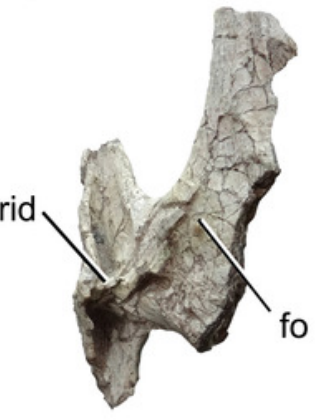


Figure 5

Caudal vertebra of sauropod dinosaur from Zhuzhou City (ZGT013).

A, left lateral view; B, right lateral view; C, anterior view; D, posterior view; E, dorsal view; F, ventral view. Abbreviation: rid, ridge. 

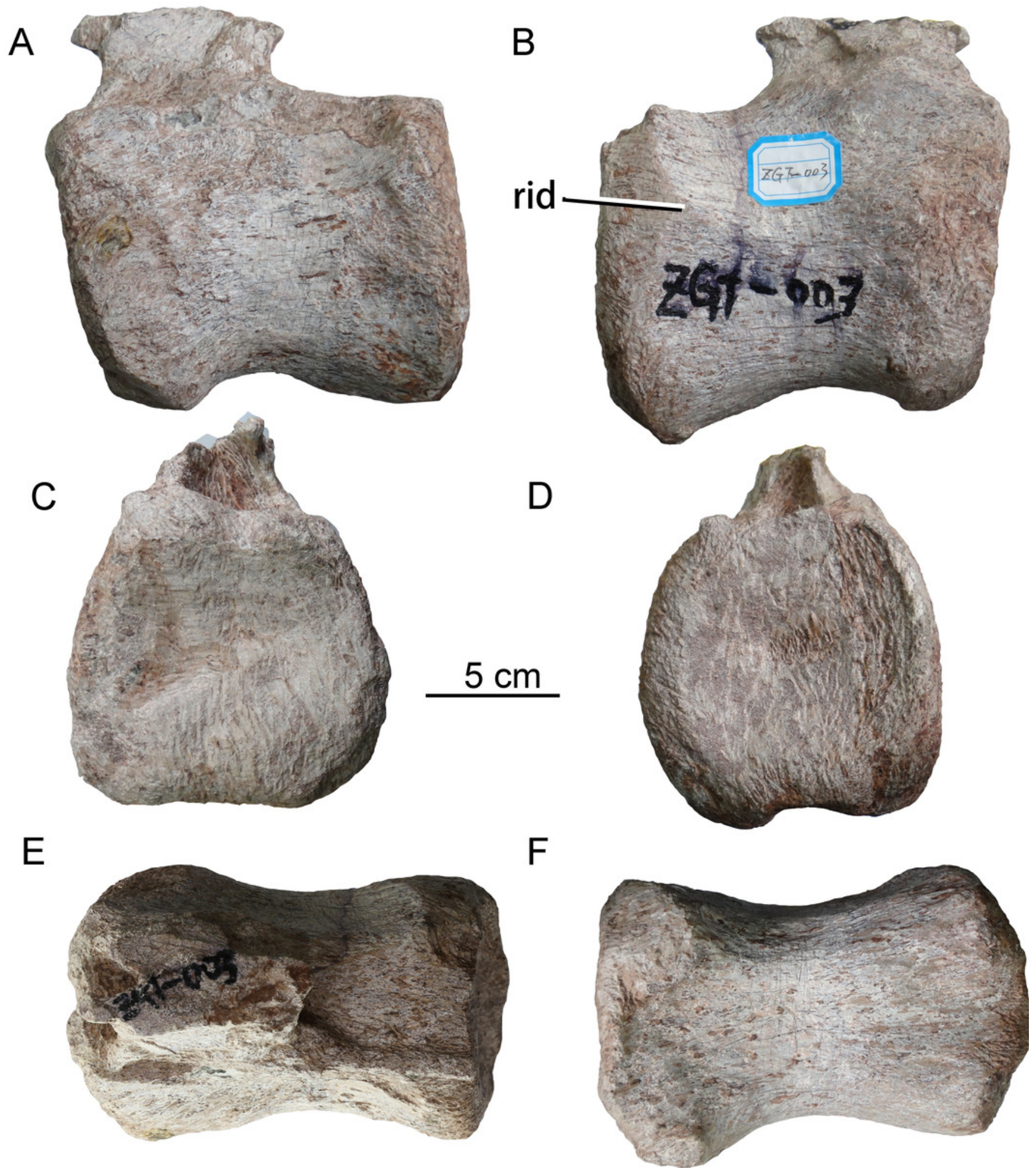


\section{Figure 6}

Humeri of sauropod dinosaurs from Zhuzhou City.

(A-E) ZGT056-060, partial right humerus. A. anterior view; B, lateral view; C, posterior view;

D, proximal view; E, distal view of broken surface (F-H) ZGT089, partial left humerus. F, distal view of broken surface; $\mathrm{G}$, anterior view; $\mathrm{H}$, posterior view. Abbreviations: dp, deltopectoral crest; $\mathbf{h} \mathbf{h}$, humeral head, Ibh, lateral bulge of humerus; hplc, humeral proximolateral corner.
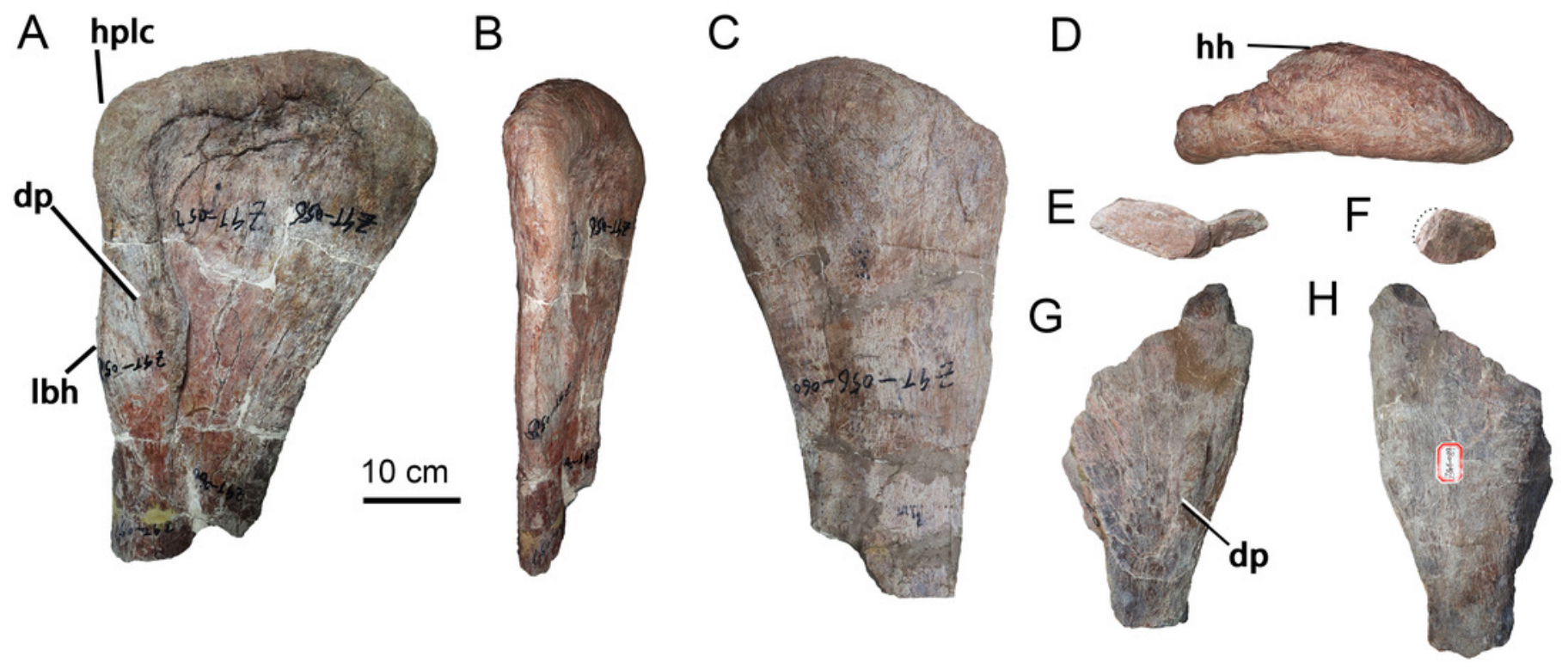


\section{Figure 7}

Complete left ischium of sauropod dinosaur from Zhuzhou City (ZMW148).

A, left lateral view. B, enlargement of the proximal region in lateral view; $C$, proximal region in dorsolateral view; D, proximal region in posterolateral view. Abbreviations: acet, acetabulum. pped, pubic peduncle; ilped, iliac peduncle

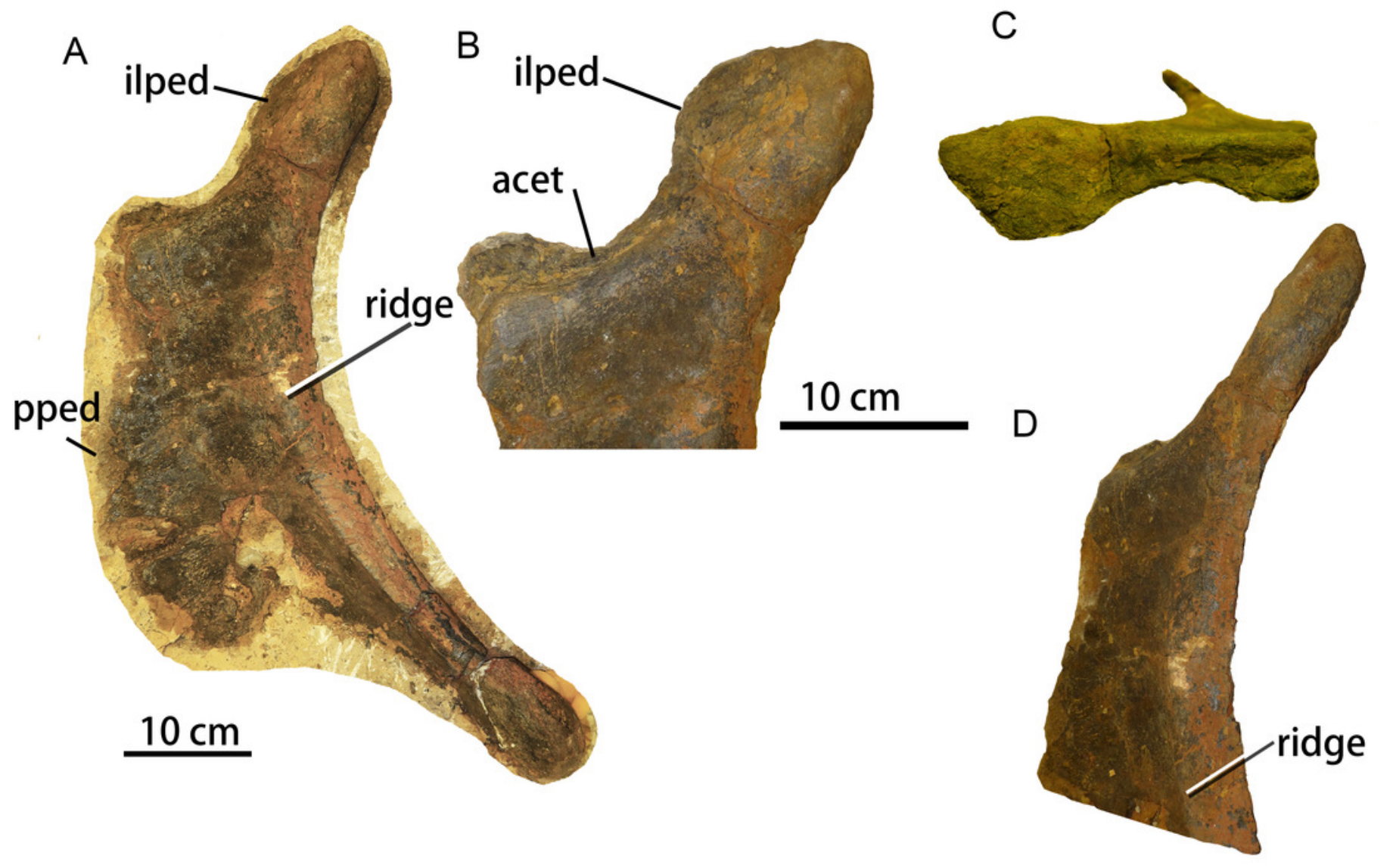




\section{Figure 8}

Right fibula and ungual of sauropod dinosaurs from Zhuzhou City.

(A-D) ZMW51-57, nearly complete right fibula. A. right lateral view; B, medial view; C, proximal view; D, distal view. (E-G) ZMW013, a pedal ungual . E, left lateral view; F, right lateral view; G. dorsal view; H, proximal view; I, ventral view. Abbreviations: rid, ridge.

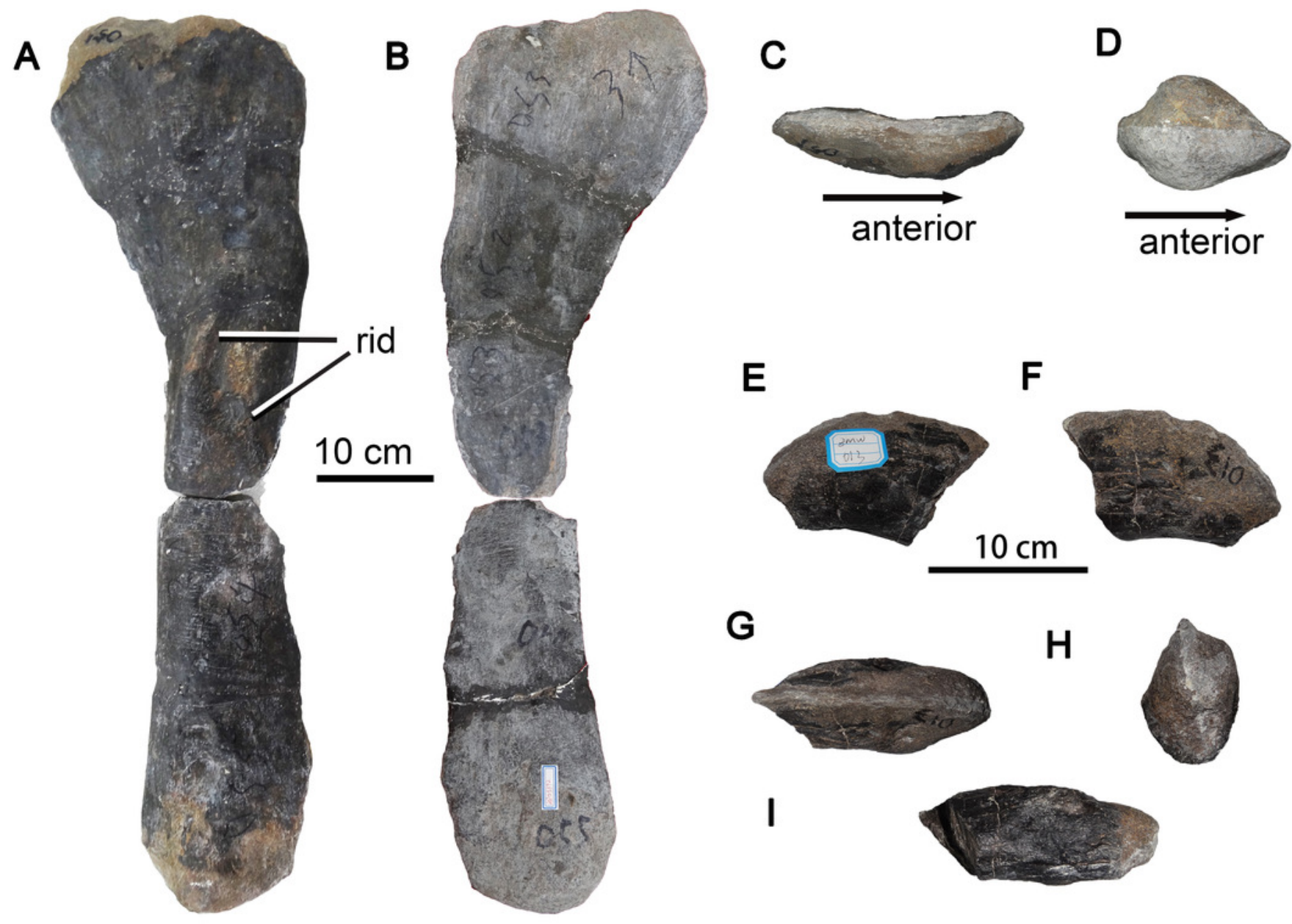




\section{Table $\mathbf{1}$ (on next page)}

Measurements of the cervical and caudal vertebrae of sauropod dinosaurs from the Upper Cretaceous Daijiaping Formation of southern China (All measurements are in millimetres). 
3

4

\begin{tabular}{|c|c|c|}
\hline Elements & Dimension & Measurements \\
\hline \multirow[t]{18}{*}{ Cervical vertebra ZGT002 } & Preserved centrum length (including ball) & 159 \\
\hline & Preserved centrum length (excluding ball) & 106 \\
\hline & Anterior centrum height & 62.0 \\
\hline & Anterior centrum width & 122 \\
\hline & Preserved posterior centrum height & 77.7 \\
\hline & Preserved posterior centrum width(dorsal) & 64.5 \\
\hline & Preserved posterior centrum width(mid shaft) & 32.7 \\
\hline & Neural arch height anteriorly & 58.5 \\
\hline & Neural arch width anteriorly & 33.6 \\
\hline & Width across prezygapophyses & 85.7 \\
\hline & Anterior pneumatopore length & 31.6 \\
\hline & Anterior pneumatopore height & 22.4 \\
\hline & Posterior pneumatopore length & 67.7 \\
\hline & Septum to posterior margin & 105 \\
\hline & Posterior pneumatopore height(anterior) & 21.3 \\
\hline & Anterior condyle width & 55.7 \\
\hline & Anterior condyle height & 98.6 \\
\hline & Preserved cervical rib length & 105 \\
\hline \multirow[t]{12}{*}{ Caudal vertebra ZGT003 } & Centrum length & 143 \\
\hline & anterior centrum height (without chevron facets) & 106 \\
\hline & $\begin{array}{l}\text { anterior centrum width (ventral } / \mathrm{mid} / \text { dorsal } \\
\text { regions) }\end{array}$ & $103 / 106 / 70$ \\
\hline & $\begin{array}{l}\text { posterior centrum height (without chevron } \\
\text { facets) }\end{array}$ & 106 \\
\hline & $\begin{array}{l}\text { posterior centrum width (ventral/mid/dorsal } \\
\text { regions) }\end{array}$ & $92 / 99.6 / 76.8$ \\
\hline & Centrum height at the mid region & 96.2 \\
\hline & Centrum width at the mid region & 82.6 \\
\hline & Neural arch length (shortest) & 67.9 \\
\hline & Neural arch width (mid region) & 55.0 \\
\hline & Neural arch height & 43.4 \\
\hline & Neural canal width/height (proximal end) & $35.0 / 38.4$ \\
\hline & Neural canal width/height (distal end) & $19.9 / 36.4$ \\
\hline
\end{tabular}




\section{Table 2 (on next page)}

Measurements of the humeri of sauropod dinosaurs from the Upper Cretaceous Daijiaping Formation of southern China (All measurements are in millimetres). 


\begin{tabular}{lll}
\hline Elements & Dimension & Measurements \\
\hline Right humerus ZGT56-60 & Preserved length (medial/lateral margin) & $552 / 470$ \\
& Proximal end maximum mediolateral width & 345 \\
& Proximal end maximum anteroposterior thickness & 92.9 \\
& Distance from proximal end to distal edge of dtp & 420 \\
& crest & \\
& Preserved mimimum shaft circumference & 410 \\
& Mediolateral width at midshaft & 175 \\
& Anteroposterior width at midshaft & 43.95 \\
& Dtp crest width (largest)/humerus width & $94.0 / 215$ \\
Left humerus ZGT089 & 318 \\
& Largest transversely width as preserved & 151 \\
& Distance from proximal end to distal edge of dtp & 260 \\
& crest & \\
& Preserved mimimum shaft circumference & \\
& Mediolateral width at midshaft & 68.3 \\
& Anteroposterior width at midshaft & 48.9 \\
& Dtp crest width (largest)/humerus width & $56.7 / 151$ \\
\hline
\end{tabular}

3 


\section{Table 3(on next page)}

Measurements of the ischium, fibula and ungual of sauropod dinosaurs from the Upper Cretaceous Daijiaping Formation of southern China (All measurements are in millimetres) 
1

\begin{tabular}{lll}
\hline Elements & Dimension & Measurements \\
\hline Left ischium ZMW148 & Length & 595 \\
& Anteroposterior length of iliac peduncle & 79.2 \\
& Maximum mediolateral width of iliac peduncle & 90.7 \\
& Dorsoventral height of iliac peduncle & 167 \\
& Anteroposterior length of acetabulum & 76.8 \\
& Anteroposterior length of proximal plate & 153 \\
& Dorsoventral height of pubic peduncle & 340 \\
& Maximum dorsoventral height of distal blade & 225 \\
& Maximum mediolateral width of distal blade & 31.4 \\
& Maximum anteroposterior length of distal blade & 60.2 \\
& Length & 736 \\
& Length from the proximal end to the proximal $/$ & $250 / 330$ \\
& distal end of the lateral trochanter & \\
& Mediolateral width of proximal end & 43.3 \\
& Anteroposterior length of proximal end & 225 \\
& Mediolateral width at midshaft & 32.2 \\
& Anteroposterior width at midshaft & 92.6 \\
Minimum shaft circumference & 228 \\
Pedal ungual ZMW013 & Mediolateral width of distal end & 75.6 \\
& Anteroposterior width of distal end & 129 \\
& Maximum proximodistal length & 137 \\
& Proximal end dorsoventral height & 83.5 \\
& Proximal end mediolateral width & 47.9 \\
\hline
\end{tabular}

